\title{
A revision of the Dibrachys cavus species complex (Hymenoptera: Chalcidoidea: Pteromalidae)
}

\author{
RALPH S. PETERS ${ }^{1,3} \&$ HANNES BAUR ${ }^{2}$ \\ 'Zoologisches Forschungsmuseum Alexander Koenig, Adenauerallee 160, 53113 Bonn, Germany. E-mail: r.peters@z.fmk.de \\ ${ }^{2}$ Department of Invertebrates, Natural History Museum, Bernastrasse 15, 3005 Bern, Switzerland. E-mail: hannes.baur@nmbe.ch \\ ${ }^{3}$ Corresponding author
}

\begin{abstract}
The taxonomy and host ranges of the cavus species complex within Dibrachys Förster (Chalcidoidea: Pteromalidae) are revised. Examination of about 810 specimens, including multivariate morphometric analysis of 21 quantitative characters clearly separated three species, Dibrachys microgastri (Bouché, 1834), Dibrachys lignicola Graham, 1969, and Dibrachys verovesparum Peters \& Baur sp. n., but allowed no further subdivision of taxa according to origin, host association or previous taxonomic concepts. A neotype is designated for D. microgastri and under this name are placed in synonymy the names Dibrachys cavus (Walker, 1835) syn. n. (including eight current junior synonyms), Dibrachys clisiocampae (Fitch, 1856) syn. n. (including five current junior synonyms), Dibrachys boarmiae (Walker, 1863) syn. n., and Dibrachys elegans (Szelényi, 1981) syn. n. Dibrachys goettingenus Doganlar, 1987 syn. n. is synonymized under D. lignicola. The morphological analyses revealed several new qualitative and quantitative characters for separating taxa in this species complex and an identification key and diagnoses are provided for females and males. Dibrachys microgastri is a polyphagous generalist pupal ectoparasitoid of several different orders of holometabolous insects, whereas D. lignicola is a polyphagous ectoparasitoid of hosts in Diptera, Lepidoptera and Hymenoptera, and D. verovesparum is a primary or secondary parasitoid in nests of Vespidae.
\end{abstract}

Key words: Dibrachys microgastri, Dibrachys lignicola, Dibrachys verovesparum, taxonomy, principal component analysis (PCA), linear discriminant analysis (LDA), host range, ratio analysis

\section{Introduction}

Dibrachys Förster, 1856 (Hymenoptera: Chalcidoidea: Pteromalidae) is a genus of small parasitioid wasps that is mainly Holarctic. Individuals can be identified using the keys of Graham (1969), Bouček \& Rasplus (1991) and Bouček \& Heydon (1997). A total of 21 species (Noyes 2003) are recognized in two subgenera, Dibrachys sensu stricto and Allodibrachys Bouček (Bouček 1965). Graham (1969) and Doganlar (1987) revised the Western European and Holarctic fauna, respectively, and keyed most species. Among them, D. cavus (Walker) is the best-known species because it is the most polyphagous pteromalid known, with hundreds of host records from several insect orders including Holo- and Hemimetabola and parasitism of different stages (Peck 1963, Noyes 2003). Even though ectoparasitoids are known to be quite polyphagous (Askew \& Shaw 1986), such a broad host range is most unusual.

Within the subgenus Dibrachys, what has been identified previously as D. cavus, D. boarmiae (Walker), D. clisiocampae (Fitch), D. goettingenus Doganlar and D. lignicola Graham forms a complex called the cavus species complex. The species of this complex are distinguished from other species of the subgenus by moderate body size of less than $3 \mathrm{~mm}$, slightly reticulate lower face lacking transverse wrinkles, only slightly emarginate anterior margin of clypeus, and hyaline wings (Graham 1969, Kusevska 1977, Doganlar 1987). The recognition and separation of certain species of this complex has always proved difficult. For instance, Bouček (1965) suspected that $D$. cavus might consist of a number of cryptic species. Graham (1969: 812) admitted that the differences between $D$. cavus and D. boarmiae "are very small" and although he gave numerous distinguishing characters (p. 811-813) they are 
difficult to use because the limits of variation mostly merge and sometimes even overlap. Doganlar (1987) acknowledged the difficulties and presented an entirely new set of quantitative characters of the hypopygium that he used to distinguish most of these critical species.

During a study on parasitoids reared from bird nests (Peters 2007, Peters \& Abraham 2010), reliable identification of species of the cavus-complex was found to be very difficult. For instance, the range of variation in a single species reared under laboratory conditions from a single host specimen usually was much larger than expected and often encompassed the range of variation for two or more species considered distinct in the above studies. Conversely, cryptic species within D. cavus were suspected (e.g., Bouček 1965) which, if true, would have proved that the ecological inferences of Peters (2007) and Peters \& Abraham (2010) were flawed. This raised serious doubts concerning the validity of the taxonomic status of the putative species listed above. We thus conducted a thorough morphological study to determine the true limits of species in the cavus-complex. In particular, we examined all relevant nominal taxa and numerous specimens from various museums as well as from our own collectings and rearings. We re-considered all qualitative characters mentioned in the literature, most notably those of Graham (1969) and Doganlar (1987), and also checked many traits that had been neglected by these authors. A comprehensive quantitative character matrix was compiled, including most measurements used for calculation of standard ratios (Graham 1969), and we applied multivariate statistical methods for investigating patterns of variation. Multivariate morphometrics (Reyment et al. 1984, Claude 2008) has provided powerful tools for discovering cryptic species and subtle morphological differences, not only in Pteromalidae (Baur 2002) and other chalcidoid wasps (Polaszek et al. 2004), but also in taxa like ants (Wang \& Lester 2004) and mites (Klimov et al. 2004). The results of our morphological analyses are summarized in a key, diagnoses, and descriptions.

After completion of the taxonomic study, we critically re-examined the host relationships of each species. This was particularly illuminating for what had been interpreted as D. cavus because of its innumerable hosts. Once the taxonomic status of each species had been clarified we could address questions concerning their host ranges, including: is there really such a polyphagous parasitoid species?

\section{Material and methods}

Specimens examined. About 810 specimens were examined from the museums listed below as well as from our own field collectings and laboratory rearings. The museum acronyms are used in the "Material examined" section of each species to indicate deposition of specimens.

BMNH The Natural History Museum, London, UK

HDOU Hope Department, Oxford University, Oxford, UK

HNHM Hungarian Natural History Museum, Budapest, Hungary

IFUG Institut für Forstzoologie der Universität Göttingen, Göttingen, Germany

INHS Illinois Natural History Survey, Urbana, Illinois, USA

MDC Miktat Doganlar collection, Mustafa Kemal University, Antakya-Hatay, Turkey

MZUF Zoological Museum "La Specola", University of Florence, Florence, Italy

NMBE Naturhistorisches Museum Bern, Bern, Switzerland

NMW Naturhistorisches Museum Wien, Vienna, Austria

SMNS Staatliches Museum für Naturkunde Stuttgart, Stuttgart, Germany

USNM United States Museum of Natural History, Washington D.C., USA

ZMH Zoologisches Museum Hamburg, Hamburg, Germany

ZSM Zoologische Staatssammlung München, Munich, Germany

Special attention was paid to all nominal taxa that are included in the cavus-complex (D. cavus, D. boarmiae, D. clisiocampae, D. goettingenus and D. lignicola) and their synonyms (see Noyes 2003). Furthermore, the namebearing types and accessible information for the following names were considered: Pteromalus microgastri Bouché, which was synonymized under $D$. cavus by Graham (1969: 810) with question mark, but considered as a valid taxon by Vidal (2001) and Noyes (2003); Pteromalus perversus Walker, which was also doubtfully synonymized with D. cavus by Graham (1969: 810); Pteromalus vesparum Ratzeburg, which was synonymized with $D$. 
boucheanus (Ratzeburg) (= D. cavus) by Kurdjumov (1913: 11), but considered as a valid taxon by Graham (1969: 810); and Tritneptis elegans Szelényi, which was transferred to Dibrachys by Bouček \& Rasplus (1991: 134) and judging from the original description of the single type specimen might belong to the cavus-complex.

Some species of Dibrachys that were not treated by Graham (1969) and Doganlar (1987) are also not considered here because they obviously are not part of the cavus-complex. This includes D. kojimae (Ishii) and D. yunnanensis Yang, both of which have a short, straight occipital carina situated close to the occipital foramen and therefore belong to the subgenus Allodibrachys. Dibrachys crassiscapus Sharkov and D. koraiensis Yang both have a deeply emarginate and impressed anterior margin of the clypeus, which places them near $D$. fuscicornis (Walker) (see Graham 1969: 809).

A subset of only 198 female specimens was suitable for the morphometric analysis. All female paratypes of Dibrachys verovesparum except one (no head) were used for the analysis. For the other species, those females used in the analysis are indicated by an "A" within the "Material examined" section, with only one female measured from any series with the same data except where stated otherwise. Specimens included in the morphometric analysis included the following type material: lectotype and paralectotype of Pteromalus cavus; lectotype and paralectotype of P. boarmiae; holotype of Tritneptis elegans; syntype of Cleonymus clisiocampae; lectotype of Eupelmus cereanus Rondani; paralectotype of $P$. gelechiae Webster; neotype of Dibrachys microgastri; holotype and paratypes of $D$. verovesparum; holotype and paratypes of D. lignicola; holotype and paratypes of D. goettingenus. Specimens from two laboratory stocks were also included. The HBM stock (27 specimens) was established from specimens reared from puparia of Triarthria setipennis (Fallén) (Diptera: Tachinidae) originally collected in Hamburg-Bramfeld, Germany, in 2004. This stock belongs to the group cavus (see below). The HRL stock (20 specimens) was established from specimens reared from puparia of $T$. setipennis originally collected in HamburgRotherbaum, Germany, in 2006. This stock belongs to the group lignicola (see below). Laboratory rearings were done on freeze-killed puparia of Calliphora vomitoria (Linnaeus) (Diptera: Calliphoridae) in Petri dishes at room temperature. A single specimen of the HBM stock used for the morphometric analyses was reared on a pupa of Galleria mellonella (Linnaeus) (Lepidoptera: Pyralidae).

For complete data of the morphometric analyses please see Supplementary files 1 and 2. In these files, some specimens are given codes or unambiguous names that can also be found on the specimen labels; specimens named only by consecutive numbers cannot be re-associated with certain examined specimens.

Character selection. The terminology used in this study follows Gibson (1997). All specimens were examined for external features used in Pteromalidae taxonomy (e.g., Graham 1969, Bouček \& Rasplus 1991). Additional body parts that were neglected by these authors (e.g., posterior of head, lower and lateral sides of mesosoma) were also carefully examined. These characters are mentioned in the descriptions only if they proved to be of taxonomic value.

For the main morphometric analysis, 21 characters were measured (Table 1). Only females were used because most of the available types were females. Females were also more readily available than males. With regard to the choice of characters for morphometrics we mainly followed Graham (1969), which is still the standard work in this respect. We initially included 12 additional characters, but these were later excluded because they proved to be strongly correlated with the remaining characters and contained no new information.

Doganlar (1987) suggested three ratios of the hypopygium to differentiate between group cavus species: (1) greatest median width of posterior lobe:greatest sublateral width of posterior lobe; (2) hypopygium breadth:hypopygium length; (3) distance between the branches of hind edge of sublateral sclerotized area:shortest distance between anterolateral incision and interior lobe (see Doganlar 1987: 198, Fig. 11). To test the separation of D. cavus, D. clisiocampae and D. boarmiae we measured 15 genetically similar specimens of our HBM laboratory stock (slides deposited at ZMH) for the morphometric characters used by Doganlar (1987).

Measurements and equipment. Measurements for morphometrics were made with a Leitz stereomicroscope using an eyepiece micrometer ( $1 \mathrm{~mm}$ divided in 20 units). The magnification used for all characters was 160x (16x eyepiece, 10x objective lenses) with one exception, gaster length was measured at 64x (16x, 4x). Additional measurements were made with a Keyence VHX-500F digital microscope. Qualitative and additional examinations were made with a Leica M165 C stereomicroscope. For study and measurement of the hypopygia, the gaster of specimens was dissected and the hypopygium mounted in Faure's medium on a slide. For all measurements we ensured that the points of reference were equidistant from the objective of the microscope. Because the quality of museum specimens varied, no strict side preference was followed and characters were measured from the side with better condition or easier access. Distorted structures (e.g., bent flagellum or gaster) were not measured. 
Photos were taken with a Keyence VHX-500F digital microscope and modified with Adobe Photoshop CS4. Specimens for photos were taken from stock HBM, stock HRL II and the type series of D. verovesparum. HRL II is the same as HRL, except that it was collected a few years later.

TABLE 1. Characters used in the morphometric analyses.

\begin{tabular}{|c|c|c|c|}
\hline no. & character & abbreviation & definition \\
\hline 1 & head breadth & hea.b & maximum breadth of head in dorsal view \\
\hline 2 & OOL & ool.1 & minimal distance between posterior ocellus and eye (s. Graham 1969) \\
\hline 3 & POL & pol.1 & distance between posterior ocelli (s. Graham 1969) \\
\hline 4 & mouth breadth & mou.b & breadth of mouth opening (s. Graham 1969) \\
\hline 5 & malar space & msp.1 & $\begin{array}{l}\text { distance between outer mouth margin and lower eye margin (s. Graham } \\
\text { 1969) }\end{array}$ \\
\hline 6 & eye distance & eye.d & distance between eyes at level of anterior ocellus \\
\hline 7 & eye height & eye.h & maximum height of eye in lateral view \\
\hline 8 & eye breadth & eye.b & maximum breadth of eye in lateral view \\
\hline 9 & eye-toruli & et.d & $\begin{array}{l}\text { distance between outer toruli margin and inner eye margin at the level of } \\
\text { toruli }\end{array}$ \\
\hline 10 & lower face & lof.1 & $\begin{array}{l}\text { distance between lower toruli margin and lower clypeus margin (s. Gibson } \\
\text { 1997) }\end{array}$ \\
\hline 11 & scape & scp.1 & length of scape (s. Graham 1969) \\
\hline 12 & pedicel & pdl.1 & length of pedicel \\
\hline 13 & flagellum & flg.1 & length of entire flagellum (s. Gibson 1997) \\
\hline 14 & mesoscutum breadth & msc.b & maximum breadth of mesoscutum \\
\hline 15 & mesoscutum length & msc.l & length of mesoscutum (in dorsal view) \\
\hline 16 & scutellum length & sct.l & length of scutellum (including frenum) \\
\hline 17 & scutellum breadth & sct.b & breadth of scutellum at anterior margin \\
\hline 18 & marginal vein & mv.l & length of marginal vein (s. Graham 1969) \\
\hline 19 & stigmal vein & stv.l & length of stigmal vein (s. Graham 1969) \\
\hline 20 & submarginal vein & smv.1 & length of submarginal vein (s. Graham 1969) \\
\hline 21 & gaster length & gst.l & length of gaster excluding ovipositor sheaths \\
\hline
\end{tabular}

Statistical analysis. For the analysis of morphometric data, principal component (PCA) and Fisher's linear discriminant analysis (LDA) were applied. Both are ordination methods that endeavor to transform the original variables into a new system of coordinate axes whereby most of the variance is contained in the first two or three axes. Traditionally, the results are then presented as scatter plots (see Pimentel (1979) and Reyment et al. (1984) for readable accounts for biologists and Sorensen \& Foottit (1992) for a collection of illustrative applications). Though the output of PCA and LDA looks very similar, their application and interpretation differ in many ways. For a PCA, the entire data matrix is considered as a single group. The analysis then reveals the unconstrained structure of variation in the data. The method can be used for contrasting morphometric data with other sets of characters (e.g., qualitative features, molecular markers) or criteria (e.g., host association, geographic origin), which, in turn, may illuminate taxonomic relationships. For instance, if delimitation of groups based on particular hosts is congruent with non-overlapping morphometric variation as revealed by a PCA, this could support the existence of separate taxa. Concerning computation, PCA is sensitive to the magnitude of the measurements. Hence, the raw data were transformed into natural logarithms. This transformation further enables interpreting the results of a PCA in terms of size and shape. According to Jolicoeur (1963; see also Klingenberg 1996 and Claude 2008) the first component can usually be interpreted as an allometric size axis, whereas all subsequent components define the allometry free shape space. The coefficients of the first component also allow estimation of the extent of allometry present in the data whereby too much allometry might affect the use of ratios (Janzon 1986). We used the test developed by Anderson (2003, section 11.6.2) to check whether the coefficients significantly deviated from the null hypothesis of isometry. 
In contrast to PCA, a LDA necessitates that each specimen is assigned to a group before the analysis. The LDA then finds the optimal separation of those groups. Hence, contrasting groups based on different criteria, as exemplified above for PCA, would always be strongly biased and the method is thus inappropriate for such purposes. However, with the help of the coefficients of the discriminant function(s) the original variables with the highest discrimination power can be determined and used for identification keys or descriptions (usually by calculating ratios). The performance of the LDA is assessed by means of cross validation (Rencher 2002: 310), where one specimen is omitted from the analysis and classified according to the discriminant function(s) found for the remaining specimens in the data set. The number of correctly classified cases is a measure of how well the result will generalize for an independent data set.

All calculations and graphics were made with the R statistical software, version 2.12.1 (R Development Core Team 2010). For the PCA, the function "prcomp()" was used, with the options "center=TRUE" and "scale=FALSE". Eigenvalues and eigenvectors were thus calculated on the covariance matrix. In order to decide how many components to retain we plotted the scree graph (Rencher 2002: 398-399). For LDA and cross validation we applied the function "lda()" from the package "MASS", also for the log-transformed data. Priors were set to equal values for all groups. Further details for computation of all these methods can be found in Venables \& Ripley (2002) and Claude (2008). The entire morphometric data set potentially included 4158 measurements based on 21 characters for 198 specimens, but numerous characters were missing or otherwise not measurable on certain specimens (Supplementary file 1). Table 2 gives an overview of the number of missing values for each variable (totaling 159 values). In order to be able to include all specimens for the multivariate analyses, missing values were imputed with the help of the package "mice", using the default settings of the function "mice()" (Supplementary file 2).

TABLE 2. Numbers of missing values in the data set used for morphometric analyses.

\begin{tabular}{lc}
\hline character & missing values \\
\hline head breadth & 1 \\
OOL & 0 \\
POL & 1 \\
mouth breadth & 10 \\
malar space & 0 \\
eye distance & 0 \\
eye height & 0 \\
eye breadth & 1 \\
eye-toruli & 4 \\
lower face & 1 \\
scape & 2 \\
pedicel & 39 \\
flagellum & 11 \\
mesoscutum breadth & 10 \\
mesoscutum length & 17 \\
scutellum length & 15 \\
scutellum breadth & 1 \\
marginal vein & 0 \\
stigmal vein & 13 \\
submarginal vein & 13 \\
gaster length & 159 \\
\hline total missing values & 3999 \\
total measurements & \\
\hline
\end{tabular}




\section{Morphological results}

Qualitative morphology. Visual inspection of qualitative morphological traits resulted in three groups being defined within the complex. A "group lignicola" included males with a distinct lobe on the outer side of the apex of the scape (used by Graham (1969) and Doganlar (1987) to separate D. lignicola males from other Dibrachys males). Females were included as long as these could be attributed unambiguously, for instance, if they had been reared from the same host specimen as males. A "group verovesparum" was defined for those specimens lacking any metallic lustre, and a "group cavus" included all other specimens belonging to the cavus-complex that lacked any a priori recognized qualitative traits. At this stage prior to the morphometric analysis we deliberately avoided the concept of species and rather interpreted the groups in the sense of operational taxonomic units.

Principal component analysis (PCA) of body measurements, all groups. The entire data set of 21 body measurements for 198 specimens (Supplementary file 2) was subjected to a PCA to determine whether there was support for the groups cavus, lignicola and verovesparum that were delineated based on qualitative characters. Inspection of the scree graph (not shown) suggested that the first three components explained $87.7 \%$ of the total variance in the data. The first component, which explains $79.6 \%$ of the variance, clearly dominated the analysis, which is usually the case in morphometric analyses of body measurements (Jolicoeur 1963, Baur 2002). Scatterplots of first against second and first against third principal components are shown in Figure 1. Generally, the groupings are unambiguously recovered by the PCA. The second component (Fig. 1a) clearly separated group verovesparum from the other groups, while only a combination of first and third component (Fig. 1b) distinguished group lignicola from the other two groups. This reflects the fact that it was much more difficult to differentiate females of group lignicola from females of group cavus.

Principal component analysis, all groups

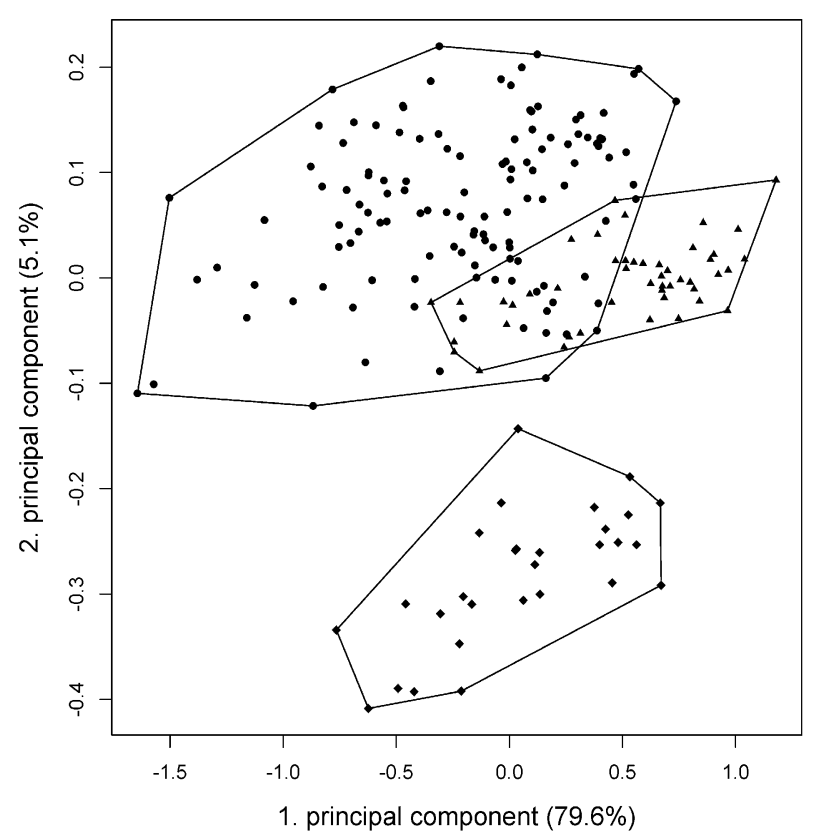

a

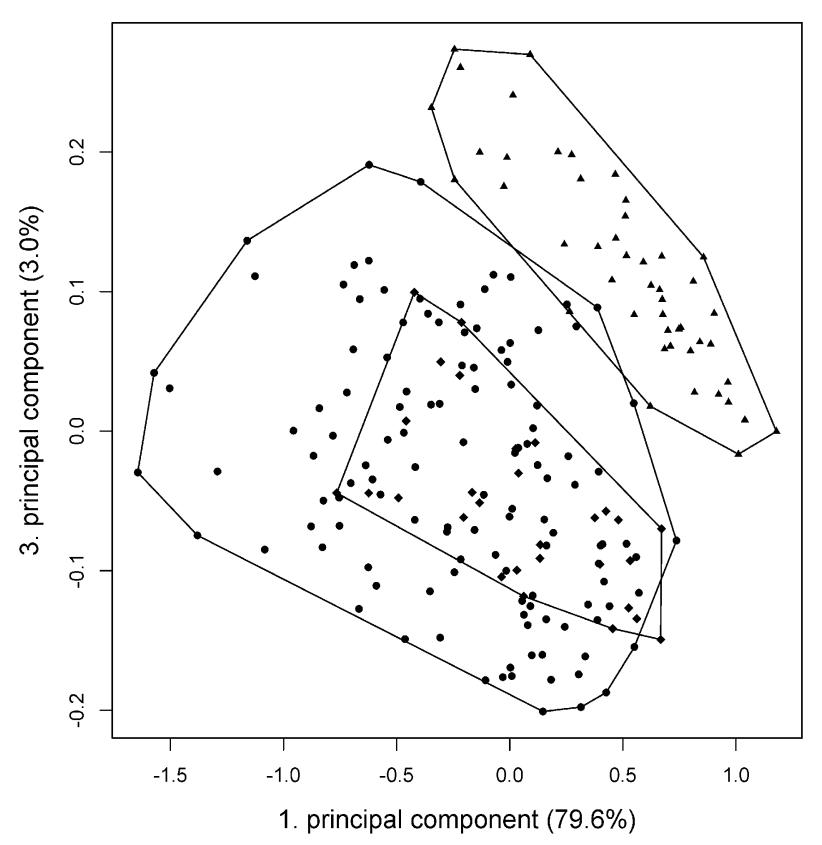

b

FIGURE 1. Result of the principal component analysis (PCA) of all groups: circles = group cavus, triangles = group lignicola, diamonds = group verovesparum . For coefficients of principal components see Table 3 .

For interpretation of the principal components, the coefficients (sometimes called loadings) of the variables have to be examined (Table 3). For the first component, the coefficients were all positive but differed to a certain extent in magnitude. Because the $\mathrm{p}$-value for Anderson's test was virtually zero $\left(\chi^{2}=406.147\right.$ and $\left.p<0.0001\right)$ and clearly rejected the null hypothesis of isometry, this component could be interpreted as an allometric size axis (Jolicoeur 1963, Klingenberg 1996). Hence, it comprised not only isometric size differences but also shape changes associated with size. According to this interpretation, the other components define the size-uncorrelated shape space in the analysis. Obviously, the separation of group verovesparum along the second component can be entirely 
attributed to allometry-free shape variation. Based on the coefficients of the second component, the relevant characters were mouth breadth, marginal vein and gaster length (Table 3). For the third component, only malar space and stigmal vein showed significant coefficients. However, combining these two characters into a ratio did itself not contribute much to the differentiation of group lignicola from group cavus, which reflects the fact that the third component explained only a marginal portion of $3.0 \%$ of the total variance in the data set.

TABLE 3. Coefficients of first three principal components (PC1-PC3) of the PCA of all groups. PC1 has positive values of roughly the same magnitude. Significant coefficients for PC2 and PC3 are indicated in bold.

\begin{tabular}{lccr}
\hline character & PC 1 & PC 2 & PC3 \\
\hline head breadth & 0.215 & -0.007 & -0.047 \\
OOL & 0.210 & -0.022 & -0.125 \\
POL & 0.187 & -0.166 & -0.271 \\
mouth breadth & 0.247 & $\mathbf{0 . 4 4 5}$ & -0.076 \\
malar space & 0.165 & -0.003 & $\mathbf{0 . 4 6 9}$ \\
eye distance & 0.207 & 0.001 & -0.162 \\
eye height & 0.220 & 0.309 & 0.020 \\
eye breadth & 0.247 & -0.022 & 0.236 \\
eye-toruli & 0.246 & -0.298 & -0.070 \\
lower face & 0.231 & 0.122 & 0.203 \\
scape & 0.183 & 0.067 & 0.021 \\
pedicel & 0.187 & -0.263 & 0.143 \\
flagellum & 0.198 & 0.023 & 0.137 \\
mesoscutum breadth & 0.250 & -0.012 & -0.086 \\
mesoscutum length & 0.248 & 0.040 & -0.147 \\
scutellum length & 0.252 & 0.027 & -0.069 \\
scutellum breadth & 0.256 & 0.026 & 0.050 \\
marginal vein & 0.152 & $\mathbf{0 . 5 6 1}$ & 0.077 \\
stigmal vein & 0.262 & -0.057 & $\mathbf{0 . 6 4 5}$ \\
submarginal vein & 0.209 & 0.037 & -0.080 \\
gaster length & 0.153 & $\mathbf{0 . 4 2 1}$ & -0.226 \\
\hline
\end{tabular}

Principal component analysis (PCA) of body measurements, separate groups. Combining several distinct groups into a single PCA can sometimes mask a more subtle but nevertheless significant structure of within-group variation. We thus performed separate analyses for each of the three groups that were delineated based on qualitative characters.

For the group cavus several important criteria were available. As mentioned previously, group cavus was split into several taxa by Graham (1969) and Doganlar (1987). Under the header "current identification", we labeled the specimens according to the characters given in their keys (identification by us or as shown on specimen label). In the case of type material the names of the respective nominal taxa were used. The material also allowed labeling of specimens with respect to geographic origin and host association. Scatterplots of the first three principal components are shown in Figure 2 (only the first two components are significant according to the scree plot, but we wanted to stay on the "safe side" by presenting the first three). The plots do not support delineation of subgroups as these were almost completely overlapping. In most instances, the variation of one particular category covers also the remaining points.

Qualitative morphology provided no clue for subdividing the group lignicola. A meaningful subgroup labeling according to host relationships and geographic origin was not possible. Taxonomically, this group comprised two nominal taxa, D. goettingenus Doganlar and D. lignicola Graham. We labeled the type specimens accordingly and added the third category "no type" for all remaining specimens. Figure 3 shows scatterplots of the first three principal components, though the scree graph suggested only the first two. The specimens labeled "no type" appear to 
a

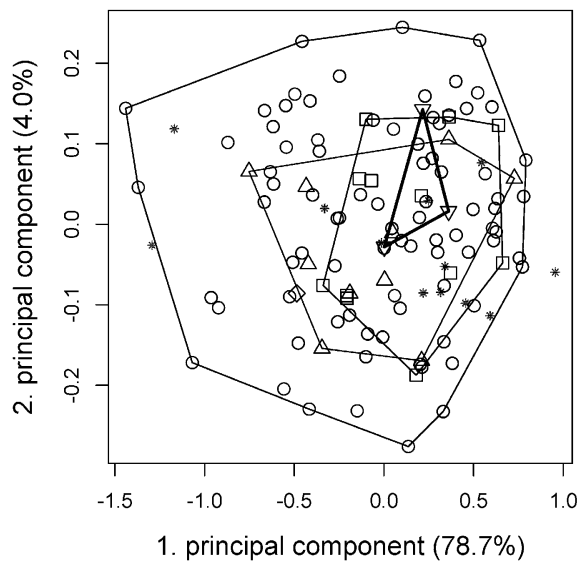

points labeled according to current identification

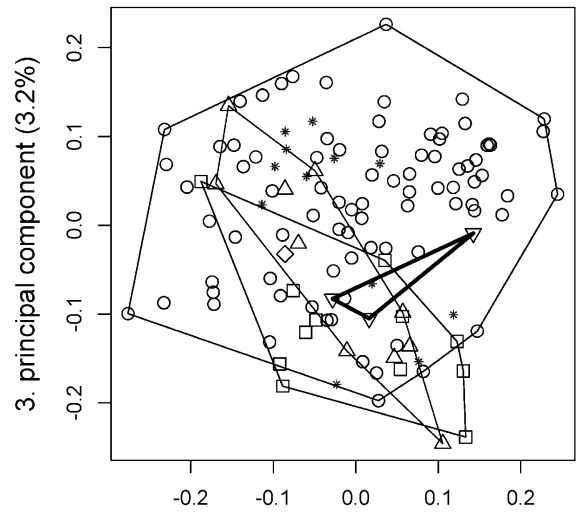

2. principal component (4.0\%)

b points labeled according to geographic origin
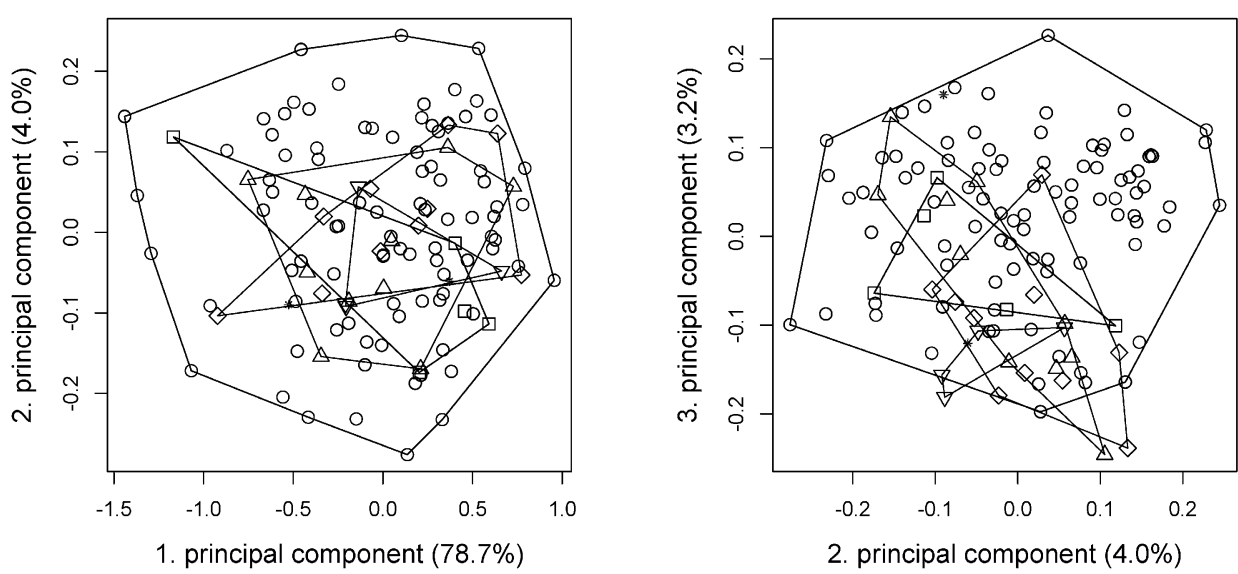

C points labeled according to host association
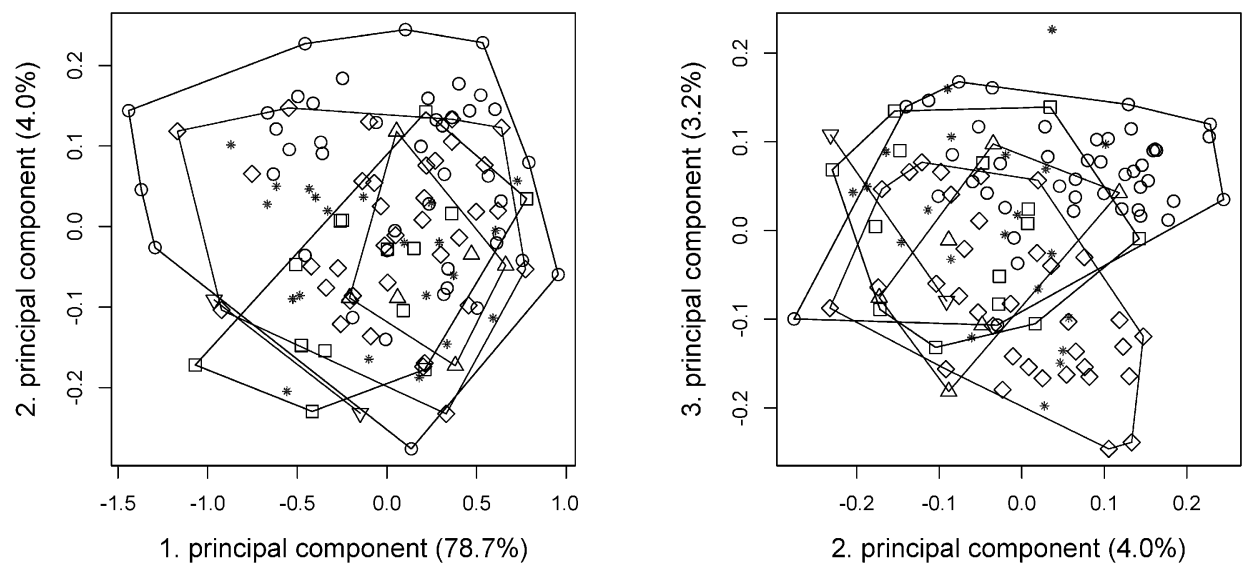

FIGURE 2. Results of the principal component analysis (PCA) of group cavus. a) specimens marked according to their current identification: circles $=$ Dibrachys cavus $($ Walker); squares $=D$. boarmiae $($ Walker); triangles $=D$. clisiocampae $($ Fitch); diamonds $=D$. elegans (Szelényi) (holotype); inverse triangles $=$ D. microgastri (Bouché) (neotype and two specimens with same data); asterisks $=$ no identification. b) specimens marked according to their place of origin: circles $=$ Europe; squares $=$ Africa; triangles $=$ America; diamonds $=$ Asia; inverse triangles $=$ Australasia; asterisks $=$ origin unknown. c) specimens marked according to their host association: circles $=$ Diptera; squares $=$ Hymenoptera parasitoids; triangles $=$ Hymenoptera non-parasitoids; diamonds $=$ Lepidoptera; inverse triangles $=$ Coleoptera or Neuroptera; asterisks $=$ host unknown . 
points labeled according to type series or no types
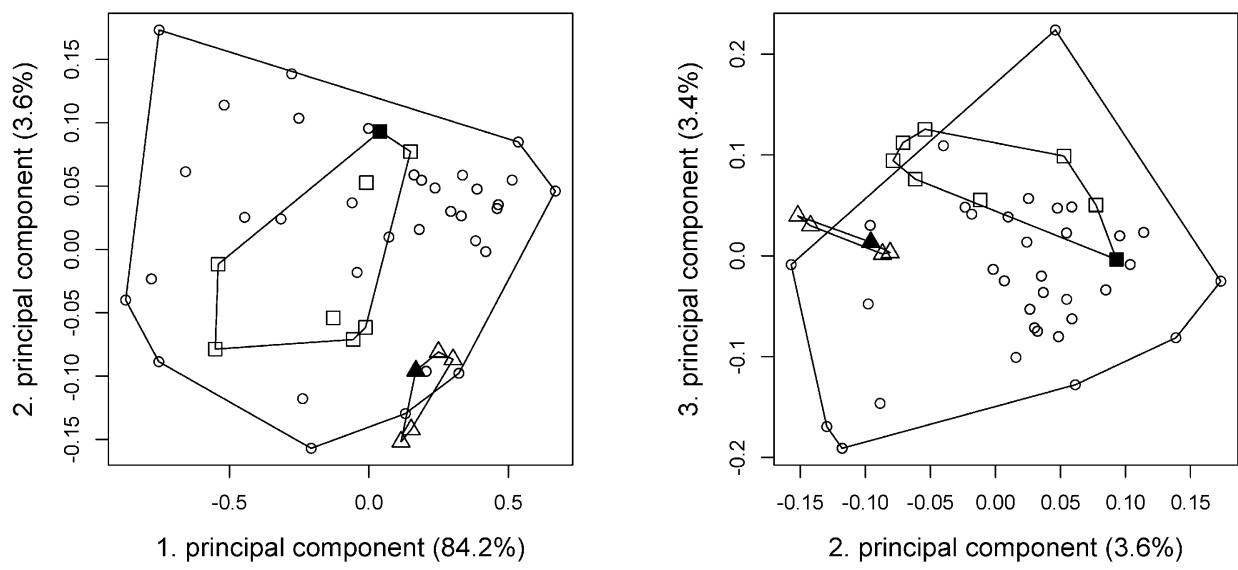

FIGURE 3. Results of the principal component analysis (PCA) of group lignicola. Specimens marked according to types series: circles = not belonging to a type series; squares = Dibrachys lignicola Graham; triangles = D. goettingenus Doganlar (filled symbols $=$ holotypes).

cover the range of variation of the type series of D. lignicola and D. goettingenus, though the ranges of the last two do not overlap. This is not surprising because the type series of both $D$. lignicola and D. goettingenus consist of very similar individuals. D. goettingenus was described from specimens reared from a single host pupa, which is why they show almost no variation. The PCA thus did not support any further subdivision of the group lignicola.

Qualitative morphology provided no clue for subdividing the group verovesparum, and no meaningful information on hosts and geographic origin was available. The PCA (not shown) revealed a fairly homogenous cluster of points.

Linear discriminant analysis (LDA) of body measurements. The entire data matrix was subjected to a LDA in order to find the best separation of the groups cavus, lignicola and verovesparum. The scatterplot in Figure 4 shows that the discriminant functions completely separated the three groups. The first function distinguished group verovesparum from the other two groups and the second function separated group lignicola from group cavus. Cross validation strongly supported this result because only two specimens of group cavus were misclassified as belonging to group lignicola (Table 4).

TABLE 4. Results of cross validation for all groups. All specimens of groups lignicola and verovesparum were correctly classified whereas only 2 of 122 specimens (1.6\%) of group cavus were misclassified as belonging to group lignicola.

\begin{tabular}{lccc}
\hline group & $\begin{array}{c}\text { classification } \\
\text { lignicola }\end{array}$ & cavus & verovesparum \\
\hline lignicola & 47 & 0 & 0 \\
cavus & 2 & 120 & 0 \\
verovesparum & 0 & 0 & 29 \\
\hline
\end{tabular}

Morphometric analysis of the hypopygium. We used the key of Doganlar (1987) to test the separation between three taxa of group cavus. First, we tried to distinguish between $D$. cavus plus D. clisiocampae and D. boarmiae based on the posterior lobe ratio (Doganlar 1987, couplet 11). This resulted in the assignment of all 15 measured specimens to the first two species (Table 8). Second, employing the hypopygial ratios 2 and 3 of Doganlar (1987, couplet 12), which he used to separate D. cavus from D. clisiocampae, 8 of 15 specimens could be assigned to D. clisiocampae and the others were found to lie beyond or between the given ranges (Table 8). In addition to the ambiguity resulting from measurement of putatively genetically similar specimens reared from a single puparium, there is the problem of accessibility of the hypopygium for easy and practical identification. The gaster has to be destroyed and slide preparation is necessary. In our view, these characters are thus not suitable for separating the species in question. 


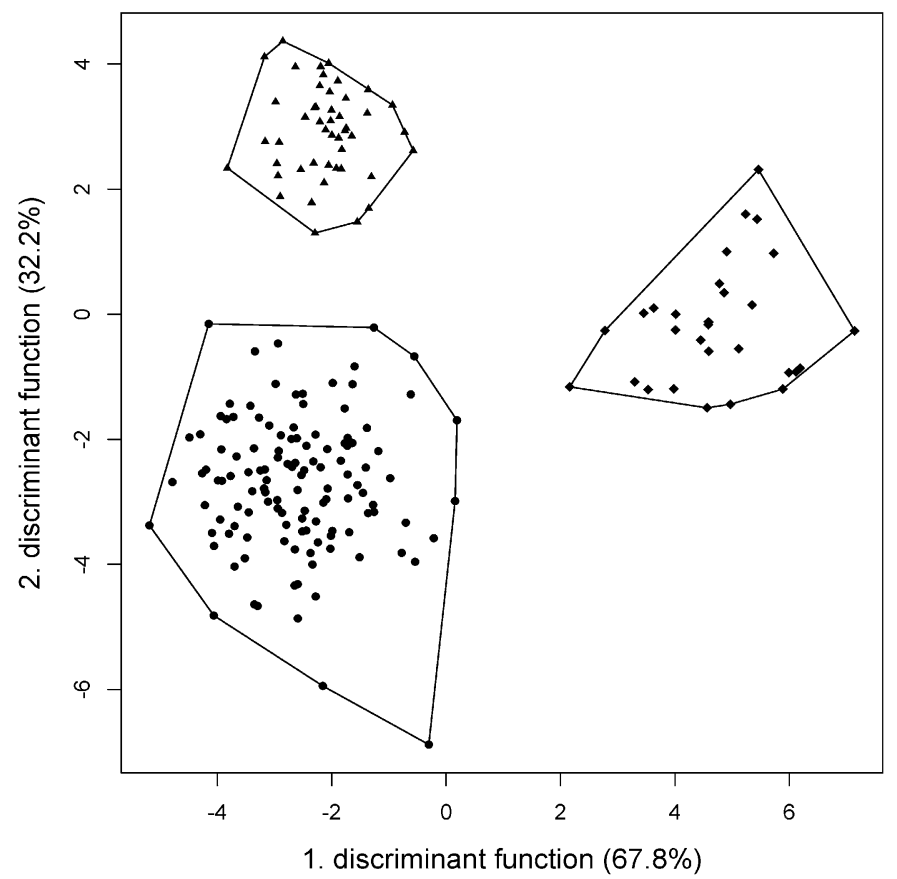

FIGURE 4. Results of the linear discriminant analysis (LDA) of all groups: circles = group cavus, triangles = group lignicola, diamonds = group verovesparum. For coefficients of discriminant functions see Table 5; see also results of cross validation, Table 4.

Finding the best character ratios for use in key and descriptions. As demonstrated above, multivariate statistical methods like PCA and LDA are useful for analyzing similar taxa. They often reveal differences in variation that are not evident using simple uni- or bivariate character analysis. Unfortunately, the output of these methods cannot be used efficiently within keys and descriptions of a taxonomic revision. For example, it would be very awkward to include in a key the numerical results of our first discriminant function where, according to Table 5, one would have to calculate to calculate $-7.31 \mathrm{x}$ head breadth $+1.49 \mathrm{x}$ OOL $+\ldots+-3.96 \mathrm{x}$ gaster length for separating group verovesparum from the remaining groups. Of course, one could reduce the number of characters in the model by a variable selection procedure (Rencher 2002: 293-296), but even such a reduced model would still be unpractical. What is usually done in such instances is to calculate ratios, as for example Graham (1969), which also reflect geometric differences in a very intuitive manner. To our knowledge, no mathematical consistent framework exists for the interpretation of numerical results of PCA and LDA in terms of ratios. We therefore developed a graphical approach for finding the optimal ratios. First, discriminant functions (DF) were checked for significant variable coefficients. For instance, DF1 separated group verovesparum from the other two groups (Fig. 4). The most significant coefficients of DF1 involved head breadth, POL, mouth breadth, eye distance and eye height (Table 5). Second, from these five characters all informative ratios were calculated (for $\mathrm{p}$ variables there are $\mathrm{p}(\mathrm{p}-1) / 2$ ratios). Of the resulting 10 ratios those with the highest discriminating power were finally sorted out by visual inspection of scatter- and boxplots. The best ratios were in this case eye height:POL and head breadth:mouth breadth (Fig. 5, Table 6). The same procedure was applied for the separation of group lignicola from group cavus. DF2 was relevant here and revealed gaster length:eye breadth and head breadth:stigmal vein as the best discriminating characters (Fig. 6, Table 7). The specimen of group cavus that lies within the range of group lignicola is one of those misclassified with cross validation above. It is noteworthy that with just two ratios almost the same discrimination power is achieved as with DF2. 
TABLE 5. Coefficients of the two linear discriminant functions (DF1 and DF2) of the LDA of all groups. Significant coefficients are indicated in bold.

\begin{tabular}{|c|c|c|}
\hline character & DF 1 & DF 2 \\
\hline head breadth & -7.31 & -9.74 \\
\hline OOL & 1.49 & 0.33 \\
\hline POL & 7.88 & -1.33 \\
\hline mouth breadth & 10.92 & 0.56 \\
\hline malar space & 0.90 & -3.84 \\
\hline eye distance & 7.97 & 2.55 \\
\hline eye height & -17.39 & 1.15 \\
\hline eye breadth & -1.84 & 15.93 \\
\hline eye-toruli & 5.79 & 2.48 \\
\hline lower face & -4.08 & 2.90 \\
\hline scape & 1.87 & 1.39 \\
\hline pedicel & 2.38 & -1.13 \\
\hline flagellum & 2.98 & 0.89 \\
\hline mesoscutum breadth & 4.04 & -6.48 \\
\hline mesoscutum length & -2.57 & -6.93 \\
\hline scutellum length & -2.26 & 10.41 \\
\hline scutellum breadth & -1.36 & 1.58 \\
\hline marginal vein & -3.73 & -2.75 \\
\hline stigmal vein & 0.01 & 7.57 \\
\hline submarginal vein & -0.97 & -1.61 \\
\hline gaster length & -3.96 & -10.39 \\
\hline
\end{tabular}

\section{Best ratios for group verovesparum versus rest}

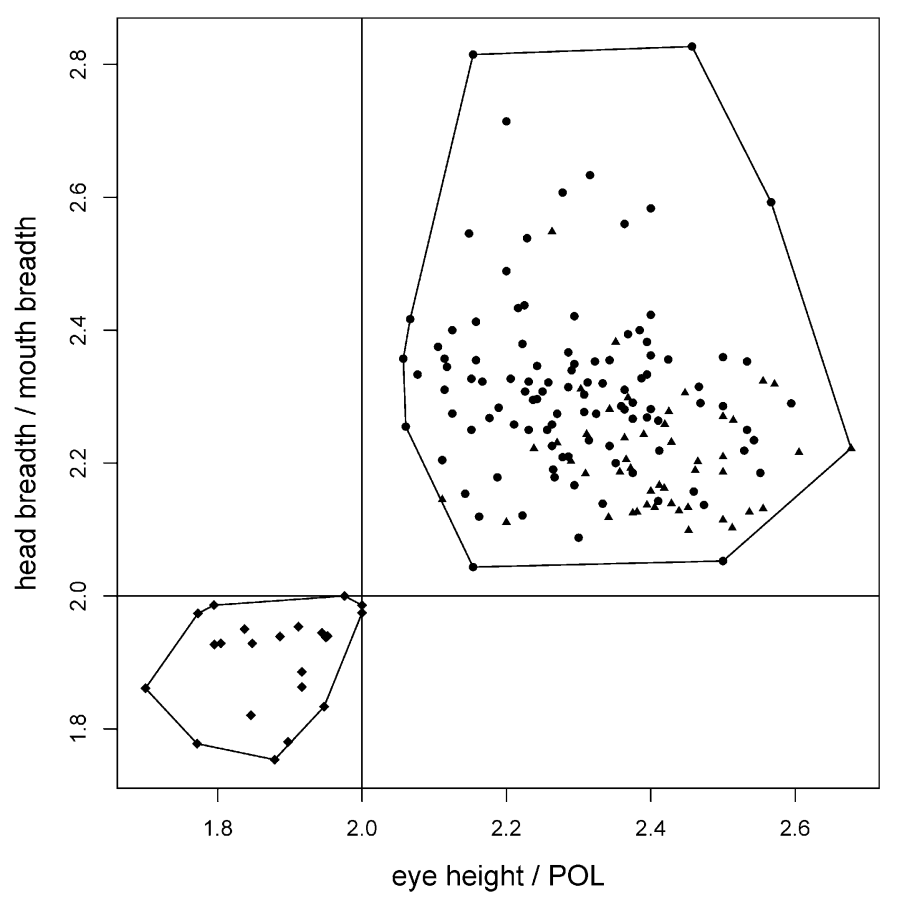

FIGURE 5. Scatterplot of the two best ratios for separating group verovesparum (diamonds) from groups cavus (circles) and lignicola (triangles) (see also Table 6). Specimens with missing values not included. 
TABLE 6. Range, interquartile range and median of best ratios separating group verovesparum from the two other groups, cavus and lignicola.

\begin{tabular}{|c|c|c|c|c|c|c|}
\hline \multirow[b]{2}{*}{ group } & \multicolumn{6}{|c|}{ eye height / POL } \\
\hline & $\min$ & 1st quartile & median & 3rd quartile & $\max$. & $\mathrm{N}$ \\
\hline verovesparum & 1.70 & 1.81 & 1.89 & 1.95 & 2.00 & 22 \\
\hline \multirow[t]{2}{*}{ rest } & 2.06 & 2.24 & 2.34 & 2.42 & 2.68 & 154 \\
\hline & \multicolumn{6}{|c|}{ head breadth / mouth breadth } \\
\hline group & $\min$ & 1st quartile & median & 3rd quartile & $\max$. & $\mathrm{N}$ \\
\hline verovesparum & 1.75 & 1.86 & 1.93 & 1.95 & 2.00 & 22 \\
\hline rest & 2.04 & 2.19 & 2.27 & 2.34 & 2.83 & 154 \\
\hline
\end{tabular}

Best ratios for group cavus versus group lignicola

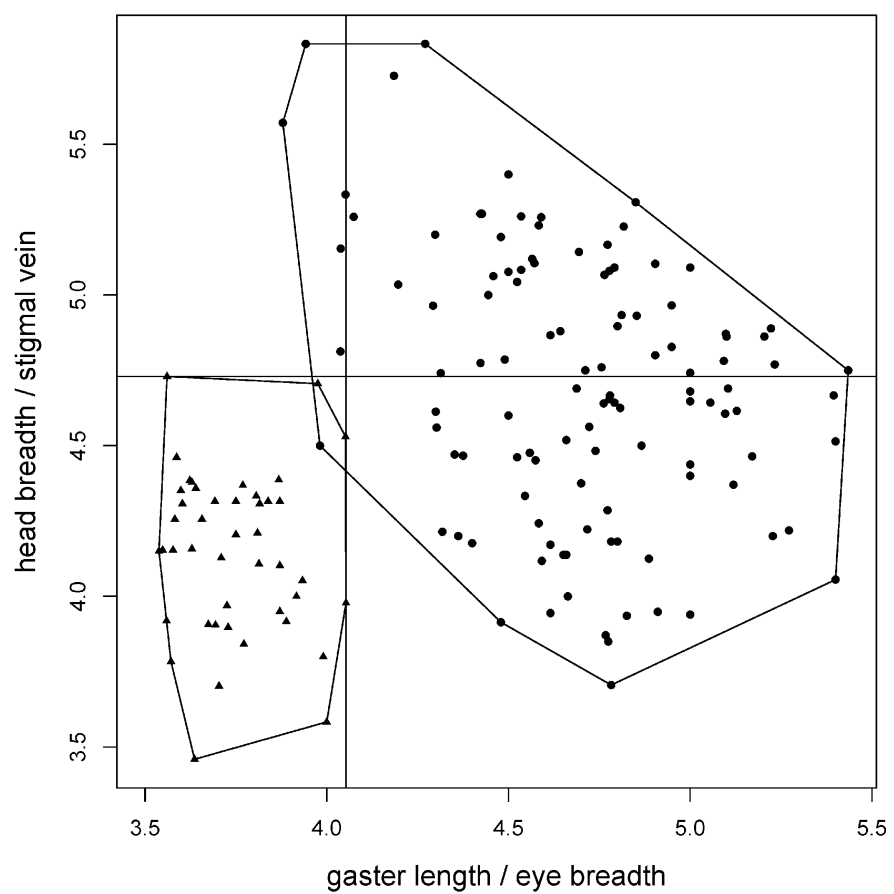

FIGURE 6. Scatterplot of the two best ratios for separating group cavus (circles) from group lignicola (triangles) (see also Table 7). Specimens with missing values not included.

Summary of morphological analyses. The material examined through morphometric analyses comprised only three groupings that are consistent with group verovesparum, group lignicola, and group cavus delineated through preliminary morphological analysis. We interpret group verovesparum as a new species. Group lignicola included two nominal taxa, D. lignicola and D. goettingenus, which lack qualitative or quantitative morphological differences. Group cavus included four valid nominal taxa, D. cavus, D. boarmiae, D. clisiocampae, and D. elegans, but specimens attributable to these names also showed no detectable differences relative to morphology, geographic origin or host association, i.e. we found no evidence that these names represent separate species or of cryptic species within $D$. cavus itself. Our analyses imply the presence of only three valid species. Because of this we propose the synonymy of $D$. cavus, $D$. boarmiae, D. clisiocampae and D. elegans under D. microgastri, but for the sake of continuity retain the informal group name "cavus-complex" for the group of three recognized species. 


\section{Taxonomy}

\section{Key to species of the cavus species complex}

1 Eyes smaller, eye height equal to or less than 2.0x POL. Head and mesosoma black, without metallic gloss or with only slight tinges of bronze, brown or green $\ldots \ldots \ldots \ldots \ldots \ldots \ldots \ldots \ldots \ldots \ldots \ldots \ldots \ldots \ldots \ldots \ldots \ldots \ldots \ldots$ verovesparum Peters \& Baur sp. n. Eyes larger, eye height more than 2.0x POL. Head and body usually with distinct metallic green, blue or bronze gloss, espe-

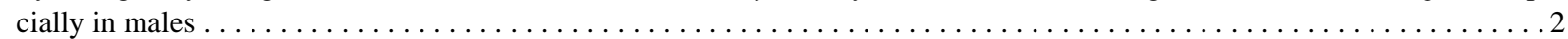

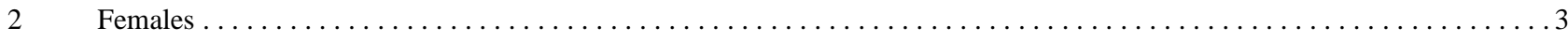

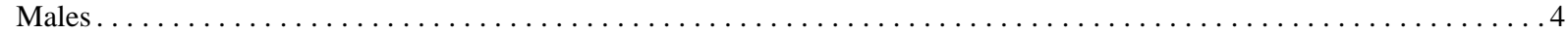

3 Usually, gaster length equal to or less than $4.05 \mathrm{x}$ eye breadth and head breadth equal to or less than 4.73x stigmal vein;

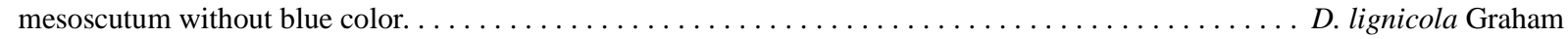
Usually, gaster length more than $4.05 x$ eye breadth or head breadth more than $4.73 x$ stigmal vein; mesoscutum sometimes with tinge of or distinct blue color $\ldots \ldots \ldots \ldots \ldots \ldots \ldots \ldots \ldots \ldots \ldots \ldots \ldots \ldots \ldots \ldots \ldots \ldots \ldots \ldots \ldots \ldots \ldots$ microgastri Bouché Outer side of apex of scape and pedicel with distinct lobe (Fig. 9e); gaster with distinct ventral testaceous spot (Fig. 9b) .... .

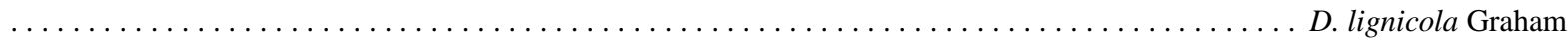
Outer side of scape and pedicel without a lobe (Fig. 9d); gaster with ventral testaceous spot absent to distinct. .......... D. microgastri Bouché

\section{Dibrachys microgastri (Bouché, 1834)}

(Figs 7a, 7d, 8a, 8d, 9a, 9d)

Diplolepis microgastri Bouché, 1834: 168, neotype female in ZMH, present designation. Syntypes presumed lost (see Graham, 1969: 811).

Pteromalus cavus Walker, 1835: 477-478, lectotype female in BMNH (B.M. TYPE no. 5.2987), designated by Graham (1969: 811) (examined by Peters); syn. $\mathbf{n}$.

Pteromalus decedens Walker, 1835: 478, lectotype female in BMNH (B.M. TYPE no. 5.2988), designated by Graham (1969: 811) (examined by Peters); synonymized with $D$. cavus by Graham (1956: 261, but see also Graham, 1969: 811); syn. $\mathbf{n}$.

Pteromalus albinervis Ratzeburg, 1844: 199, name-bearing types presumed destroyed (see comment of Graham (1969: 811) for P. tenuis Ratzeburg, 1844 and P. boucheanus Ratzeburg, 1844); synonymized with D. boucheanus by Kurdjumov (1913: 11); syn. n.

Pteromalus boucheanus Ratzeburg, 1844: 196, name-bearing types presumed destroyed (Graham, 1969: 811); Dibrachys boucheanus, combination by Thomson (1878); synonymized with D. cavus by Gahan (1938: 211); syn. n.

Pteromalus boarmiae Walker in Newman, 1863: 8609-8610 (English description accidentally transposed, see comment of Graham (1969: 812)), lectotype female in BMNH (B.M. TYPE no. 5.2989), designated by Graham (1969: 812) (examined by Peters); syn. n.

Pteromalus tenuis Ratzeburg, 1844: 195, name-bearing types presumed destroyed (Graham, 1969: 811); synonymized with $P$. boucheanus by Ratzeburg (1848: 189); syn. n.

Pteromalus zelleri Ratzeburg, 1848: 190, name-bearing types presumed destroyed (see comment of Graham (1969: 811) for $P$. tenuis Ratzeburg, 1844 and $P$. boucheanus Ratzeburg, 1844); synonymized with D. boucheanus by Kurdjumov (1913: 11); syn. n.

Pteromalus vesparum Ratzeburg, 1852: 233, name-bearing types presumed destroyed (see Graham, 1969: 809); synonymized with D. boucheanus by Kurdjumov (1913: 11); syn. n.

Cleonymus clisiocampae Fitch, 1856: 431-432, syntype female and male in USNM (USNM type no. 1831) (examined by Peters); synonymized with $D$. cavus by Gahan (1938: 211), but considered valid by Doganlar (1987: 204); syn. n.

Cheiropachus nigrocyaneus Norton, 1869: 327, syntype females in USNM (USNM type no. 61079) (examined by Peters); Pachyneuron nigrocyaneum, combination by Ashmead (1888); synonymized with D. clisiocampae by Girault (1916b: 408), with $D$. cavus by Gahan (1938: 211), and subsequently with D. clisiocampae by Doganlar (1987: 204); syn. n.

Eupelmus cereanus Rondani, 1876: 38, 40, lectotype female in MZUF (no. 32), designated by Bouček (1974: 247) (examined by Peters); synonymized with $D$. cavus by Delucchi (1955: 174); syn. n.

Pteromalus gelechiae Webster, 1883: 151, lectotype male in INHS (INHS Insect Collection 213,068), designated by Frison (1927: 220) (examined by Peters); nine paralectotypes in INHS (one female labeled "lectoallotype", INHS Insect Collection 213,069; four males and four females labeled "paratypes", INHS Insect Collection 257,879-257,886) (examined by Peters); synonymized with D. clisiocampae by Girault (1916b: 408), with D. cavus by Gahan (1938: 211), and subsequently with D. clisiocampae by Doganlar (1987: 204); syn. n.

Pteromalus chionobae Howard, 1889: 1889, syntypes in USNM (USNM type no. 2673) (examined by Peters); synonymized with $D$. clisiocampae by Girault (1916b: 408), with $D$. cavus by Gahan (1938: 211), and subsequently with $D$. clisiocampae by Doganlar (1987: 204); syn. n.

Arthrolytus apatelae Ashmead, 1893: 162, syntypes in USNM (USNM type no. 26215 examined by Peters); Dibrachys apate- 
lae, combination by Girault (1916b); synonymized with $D$. cavus by Gahan (1938: 211), and with D. clisiocampae by Doganlar (1987: 204); syn. n.

Arthrolytus pimplae Ashmead, 1894: 339, syntypes in USNM (USNM type no. 2182) (examined by Peters); synonymized with Arthrolytus apatelae by Girault (1916a: 297; 1916b: 408), with D. cavus by Gahan (1938: 211), and with D. clisiocampae by Doganlar (1987: 204); syn. n.

Trichomalus truyilloi Blanchard, 1938: 178, name-bearing types unknown; synonymized with D. cavus by Gahan (1942: 45); syn. $\mathbf{n}$.

Tritneptis elegans Szelényi, 1981: 178, holotype female in HNHM (Hym. Typ. nr. 6821) (examined by Peters); assigned to Dibrachys by Bouček \& Rasplus (1991); syn. n.

Diagnosis. Both sexes. Eyes large, eye height greater than 2.0x POL. Head and mesosoma mostly with distinct metallic coloration, predominantly green or dark green (Figs 7a, 7d, 8a, 9a), but sometimes distinctly blue or with distinct blue tinge on mesoscutum.

Female. Gaster long and eyes elongate, gaster length usually greater than $4.05 x$ eye breadth $(3.88-5.43$, but only 6 of $114 \leq 4.05$ ) (Figs $6,7 a$, Table 7). Outer margin of eyes straight or slightly to distinctly emarginate (Fig. 7a). Stigmal vein short compared to marginal vein, marginal vein usually 2.0x or more stigmal vein (1.62-2.86, but only 11 of $121<2.0$ ) (Fig. 8d). Mouth narrow, head breadth greater than 2.0x mouth breadth (Fig. 7d).

Male. Scape and pedicel apically both without lobe on outer side (Fig. 9d). Gastral spot absent to distinct (Fig. 9a).

TABLE 7. Range, interquartile range and median of best ratios separating group cavus from group lignicola.

\begin{tabular}{lcccccc}
\hline & \multicolumn{2}{c}{ gaster length / eye breadth } & & & \\
group & min. & 1st quartile & median & 3rd quartile & max. & $\mathrm{N}$ \\
\hline lignicola & 3.54 & 3.63 & 3.73 & 3.87 & 4.05 & 44 \\
cavus & 3.88 & 4.50 & 4.72 & 4.90 & 5.43 & 113 \\
\hline \multicolumn{7}{c}{ head breadth / stigmal vein } \\
group & min. & 1st quartile & median & 3rd quartile & max. & $\mathrm{N}$ \\
\hline lignicola & 3.46 & 3.94 & 4.16 & 4.32 & 4.73 & 44 \\
& 3.71 & 4.40 & 4.69 & 5.06 & 5.83 & 113 \\
\hline
\end{tabular}

Description. FEMALE (Figs 7a, 7d, 8a, 8d). Body length 1700-2950 $\mu \mathrm{m}$.

Head (Figs 7a, 7d). Eyes large and elongate, sometimes kidney shaped, outer margin straight or slightly to distinctly emarginate; eye 1.39-1.83x as high as broad; eye height 2.05-2.59x POL. Level of lower margin of antennal toruli at level of lower ocular line. Clypeus distinctly striate vertically, though less distinct towards lower margin. Lower face only moderately receding. Mouth narrow, head breadth 2.04-2.83x mouth breadth, mouth breadth 1.73-2.95x malar space. POL 1.55-2.31x OOL. First anellus transverse, second anellus slightly longer than broad; first funicular segment slightly longer than broad, second to fifth quadrate, and sixth slightly transverse; flagellum 0.61-0.80x head breadth. 


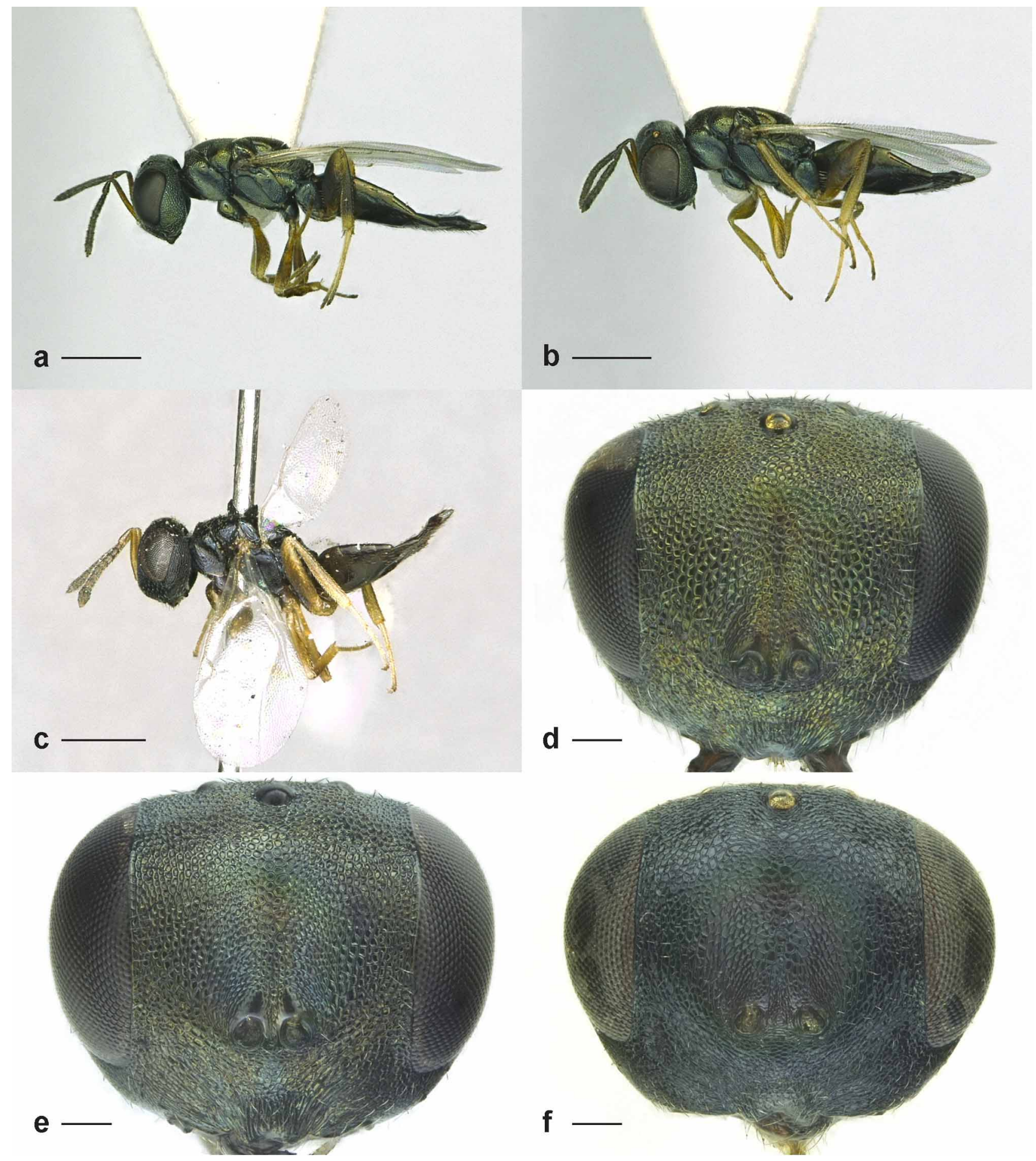

FIGURE 7. a-c, habitus (lateral) of female: (a) Dibrachys microgastri (Bouché); (b) D. lignicola Graham; (c) D. verovesparum Peters \& Baur, holotype. $\mathrm{d}-\mathrm{f}$, head (frontal) of female: (d) D. microgastri; (e) D. lignicola; (f) D. verovesparum. Scale bars a-c $=500 \mu \mathrm{m} ; \mathrm{d}-\mathrm{f}=100 \mu \mathrm{m}$.

Mesosoma (Fig. 8a). Mesoscutum and scutellum slightly convex in lateral view. Mesoscutum 0.46-0.68x as long as broad. Reticulation coarse, 11.7-14.5 meshes/200 $\mu \mathrm{m}$ in anterior part of mesoscutum, sometimes finer on scutellum than on mesoscutum. Marginal rim of scutellum only moderately turned upwards. Plicae weak and straight; median carina occasionally missing or interrupted.

Wings (Fig. 8d). Wings hyaline; stigmal vein short, marginal vein 1.62-2.86x stigmal vein; submarginal vein 1.4-2.2x marginal vein. 

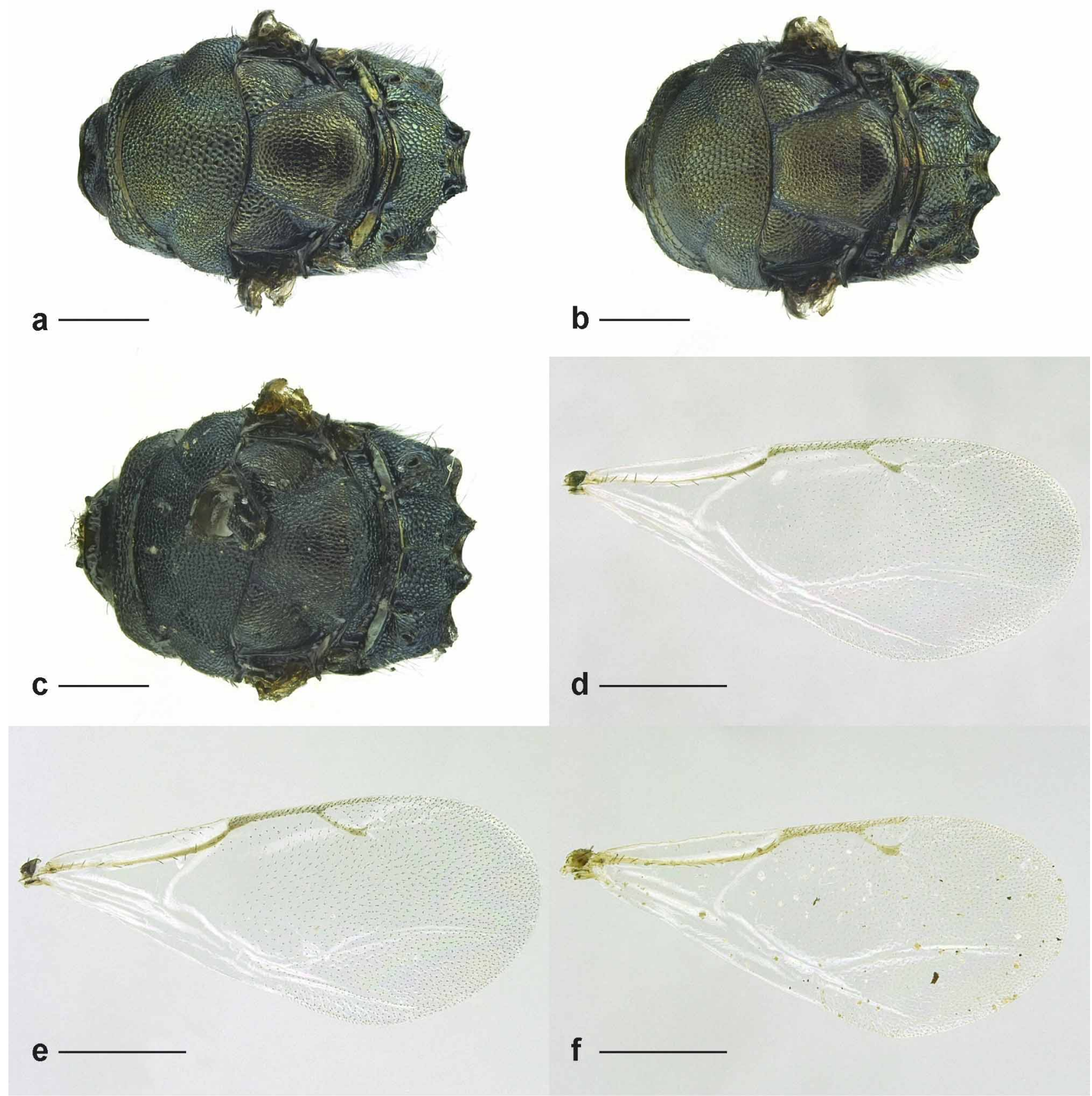

FIGURE 8. a-c, mesosoma (dorsal) of female: (a) Dibrachys microgastri (Bouché); (b) D. lignicola Graham; (c) D. verovesparum Peters \& Baur. d-f, forewing of female: (d) D. microgastri; (e) D. lignicola; (f) D. verovesparum. Scale bars a-c $=250 \mu \mathrm{m} ; \mathrm{d}-\mathrm{f}=500 \mu \mathrm{m}$.

Metasoma (Fig. 7a). Gaster varying from almost as long as to longer than head plus mesosoma; elongate and pointed; length 3.88-5.43x eye breadth. Tergites smooth, weakly alutaceous in apical half of gaster and with strong hairs, especially in apical half; sternites with few hairs.

Hypopygium. See Table 8 (characters used by Doganlar 1987).

Color (Figs 7a, 7d, 8a, 8d). Head and mesosoma very variable, but head and dorsal surface of mesosoma always with distinct metallic coloration or black with distinct metallic tinge. Antenna varying from yellow to dark brown. Ventral surface of mesosoma black or dark brown with slight metallic tinge or with distinct metallic coloration. Venation of wings testaceous to distinctly brown. Procoxa usually concolorous with mesosoma; meso- and metacoxa sometimes concolorous with mesosoma, but mostly brown. Trochanters, femora and tibiae varying from yellow to dark brown. Tarsi varying from pale yellow to brown, segments 4 and 5 of metatarsus usually darker than others. Gaster dark brown and shiny. 
TABLE 8. Ranges of three characters of the hypopygium used by Doganlar (1987) to separate D. boarmiae, D. cavus, and D. clisiocampae, compared with ranges of specimens from the D. microgastri laboratory stock HBM $(\mathrm{N}=15)$; character $1=$ greatest median width of posterior lobe:greatest sublateral width of posterior lobe; character $2=$ hypopygium breadth:length; character $3=$ distance between the branches of hind edge of sublateral sclerotized area:shortest distance between anterolateral incision and interior lobe.

\begin{tabular}{llll}
\hline & character 1 & character 2 & character 3 \\
\hline D. boarmiae & $1.00-1.07$ & - & - \\
D. cavus & $1.21-1.41$ & $1.65-1.70$ & $1.33-1.63$ \\
D. clisiocampae & $1.21-1.41$ & $1.85-2.00$ & $1.83-2.90$ \\
D. microgastri stock HBM & $1.22-1.50$ & $1.78-2.08$ & $1.71-2.25$ \\
\hline
\end{tabular}

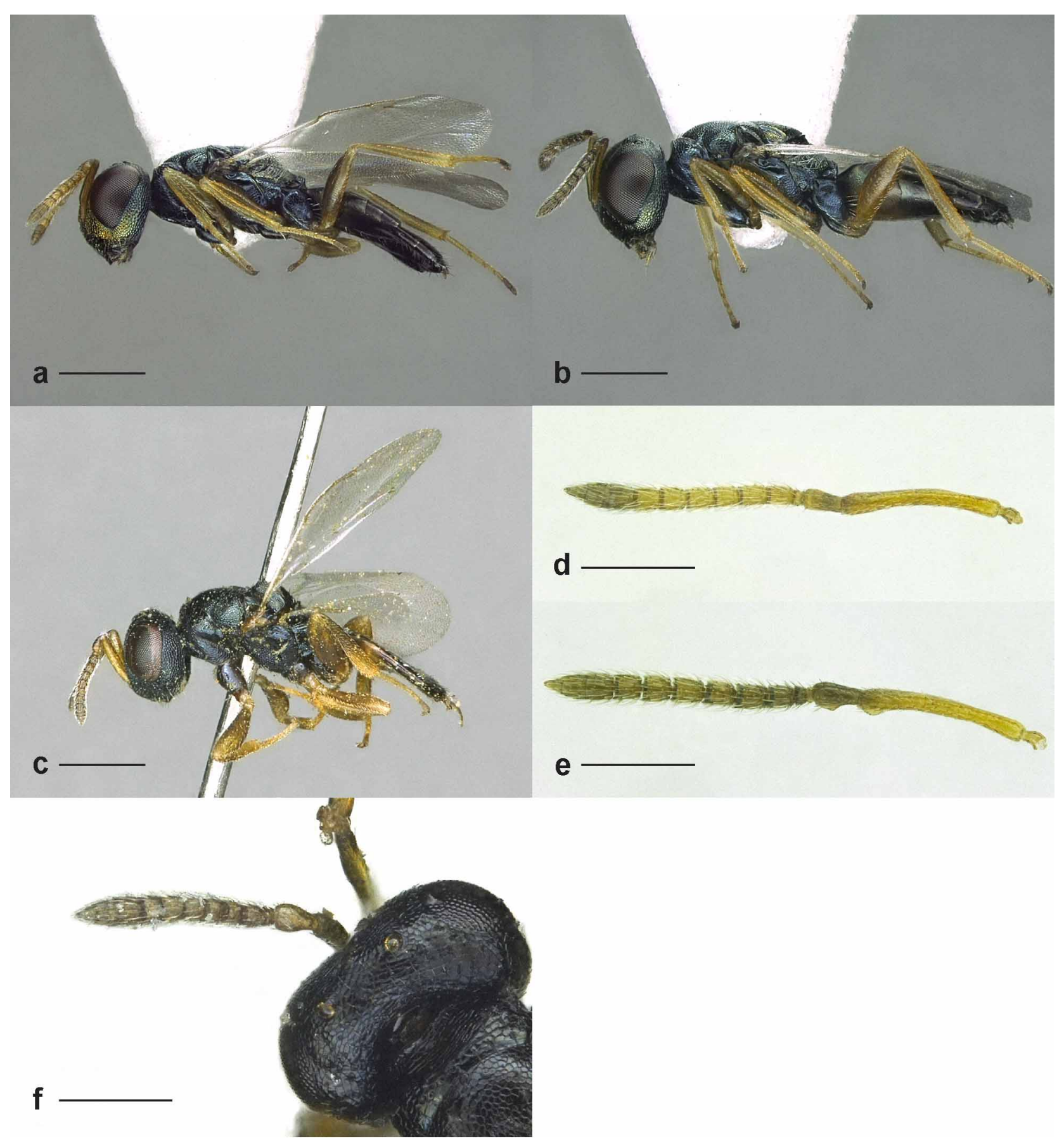

FIGURE 9. a-c, habitus (lateral) of male: (a) Dibrachys microgastri (Bouché); (b) D. lignicola Graham; (c) D. verovesparum Peters \& Baur. d and e, antenna (dorsal) of male: (d) D. microgastri; (e) D. lignicola. f, head with antenna (dorsal) of male; D. verovesparum. Scale bars $\mathrm{a}-\mathrm{c}=500 \mu \mathrm{m} ; \mathrm{d}-\mathrm{f}=250 \mu \mathrm{m}$. 
MALE (Figs 9a, 9d). Similar to female except as follows. Smaller, body length 1450-2360 $\mu$ m.

Head. Eyes not emarginate and more circular in shape; eye height 2.11-2.60x POL. Level of lower margin of antennal toruli slightly above lower ocular line. Scape and pedicel apically without lobe on outer side.

Metasoma. Gaster distinctly shorter than rest of body, 0.63-0.93x length of head plus mesosoma; elongate, not distinctly pointed, broader than in female.

Color. Head always with distinct metallic coloration. Antenna varying from yellow to brown, clava sometimes a little darker than rest. Mesoscutum always with distinct green or blue metallic coloration; scutellum often with distinct bronze or gold-bronze. Coxae usually brown, sometimes at least in part concolorous with mesosoma. Gaster brown with light testaceous spot on ventral side of anterior segments ("gastral spot") absent to distinct, and if distinct then also visible in dorsal view.

Material examined. Neotype female (hereby designated): Germany: Schleswig-Holstein: Halstenbek, garden of Langkoppelweg 24, N53.6197 E9.8283 (WGS84), reared from cocoon of Cotesia glomerata (Hymenoptera: Braconidae), leg. L. Krogmann 26/04/2006, det. R. Peters 2009. Deposited at ZMH (A, 1 female).

Other material: Afghanistan: Chakav, labeled "Chakav, C.I.B.C.", reared from "larva boring in branches of Juglans regia" (A, 2 females) (BMNH) (det. Dibrachys sp.). Algeria: Delassus (?), reared from Lobesia botrana (A, 9 females, 3 males) (BMNH) (det. D. cavus). Australia: Victoria, reared from Galleria mellonella (A, 1 female) (BMNH) (det. D. boarmiae); Victoria, reared from Cydia molesta, originally identified as D. australia, Korr. Bouček (A, 2 females, 1 male) (BMNH) (det. D. boarmiae). Bulgaria: reared from Cephus sp. (A, 3 females) (BMNH) (det. D. cavus). Canada: British Columbia: Burnaby, reared from Eutromula pariana, leg. Doganlar 10/ 09/1977 (all 7 females A (ZSM01-07), 3 males) (ZSM) (det. D. clisiocampae); British Columbia: Burnaby, reared from Apanteles longicauda, leg. 01/09/1977 (A, 1 female) (MDC) (det. D. clisiocampae); British Columbia: Burnaby, reared from Apanteles sp., leg. 30/08/1977 (1 male) (MDC) (det. D. boarmiae). Croatia: Rovinj, reared from Diptera puparium ( 8 females, 1 male) (ZMH) (det. D. cavus). Cyprus: reared from stored wheat (A, 9 females) (BMNH) (det. D. cavus); Nicosia, reared from Coleophora sp. (A, 1 female) (BMNH) (det. D. cavus). Czech Republic: Bohemia: Stepanov, reared from Diprion polytomum (= Gilpinia hercyniae) (A, 19 females) (BMNH) (det. D. cavus); Bohemia: Dobris, reared from Diprion polytomum (A, 3 females) (BMNH) (det. D. cavus); Bohemia: Dobris, reared from Diprion polytomum, different host specimen than previous, prob. different collection date than previous (18 females) (BMNH) (det. D. cavus); Bohemia: Holovousy, reared from tachinid puparium ex Cydia pomonella (A, 1 female) (BMNH) (det. D. cavus); Bohemia: Plese, reared from Diprion polytomum (11 females, 2 males) (BMNH) (det. D. cavus); Bohemia: Vlastijovice (?, probably wrong spelling), reared from Diprion polytomum (A, 9 females, 10 males) (BMNH) (det. D. cavus). Egypt: reared from Platyedra gossypiella (= Pectinophora gossypiella) (A, 1 female) (BMNH) (det. D. cavus); Kafr el Sheikh, reared from Galleria mellonella (7 females, 1 male) (BMNH) (det. D. boarmiae). England: no host, identified as D. fuscicornis by Walker, corrected by Bouček (A, 1 female) (BMNH) (det. D. cavus); Buckinghamshire, no host (A, 1 female) (BMNH) (det. D. cavus); Buckinghamshire, same location and different collection date than previous, no host (1 female) (BMNH) (det. D. cavus); Wiltshire: Salisbury, reared from Galleria melonella ex beehive (A, 1 female, 2 males) (BMNH) (det. D. cavus); no host (1 female) (BMNH) (det. D. cavus); no host (1 female) (BMNH) (det. D. cavus); Bristol, reared from Ocytata pallipes 18/09/1979, em. June 1980 (2 of 12 females A, 3 males) (BMNH) (det. D. cavus); Bristol, reared from Triarthria setipennis, leg. 11/10/1979, em. June 1980 (A, 7 females) (BMNH) (det. $D$. cavus); Bristol, reared from Triarthria setipennis, leg 12/10/1979, em. June 1980 (A, 6 females) (BMNH) (det. D. cavus); Worcestershire, reared from Phygadeuon pr. vexator on Triarthria setipennis (A, 6 females, 2 males) (BMNH) (det. D. cavus); Hampshire, no host (A, 5 females) (BMNH) (det. D. boarmiae); no host, lectotype of Pteromalus cavus (A, 1 female) (BMNH); no host, paralectotypes of Pteromalus cavus (A, 5 females, 1 male) (BMNH) (det. D. cavus); no host, labeled Pteromalus decendens Walker (6 females, 3 males) (BMNH) (det. D. cavus); no location (but most probably from England), no host, lectotype and paralectotype Pteromalus decedens (1 female, 1 male) (BMNH) (det. D. cavus); Kensington, reared from Orgyia antiqua (A, 7 females, 3 males) (BMNH) (det. D. cavus); London, reared from cocoons of Apanteles solitarius (A, 7 females, 4 males) (BMNH) (det. D. cavus); Cambridge, reared from puparium of Calliphora sp. (A, 7 females, 4 males) (BMNH) (det. D. cavus); Cambridge, reared from puparium of Calliphora sp., different collection date than previous (A, 2 females) (BMNH) (det. D. cavus); Cambridge, reared from puparium of Calliphora sp., different collection date than previous (2 males) (BMNH) (det. D. cavus); London: Osterley Park, reared from Triarthria setipennis, labeled Altson Collection (A, 4 females) (BMNH) (det. D. cavus); Fryer (?), reared from psychid (4 females, 1 male) (BMNH) 
(det. D. cavus); Norfolk, reared from larva of Tyria jacobeae (7 females) (BMNH) (det. D. cavus); Leeds, reared from tachinid of Acronicta psi (A, 5 females, 3 males) (BMNH) (det. D. cavus); London, no host (1 female) (BMNH) (det. D. cavus); Cheshire: Romiley, reared from Hemerobius subnebulosus (= Wesmaelius subnebulosus) cocoons (A, 5 females) (BMNH) (det. D. cavus); London, reared from pupa of Orgyia antiqua, labeled "on defoliating plane" (1 female) (BMNH) (det. D. cavus); London, reared from Orgyia antiqua larva, labeled "on defoliating planes", probably same location as previous (A, 14 females, 6 males) (BMNH) (det. D. cavus); Essex, reared from pupae of Apanteles sp. from Leucoma salicis (A, 41 females and males) (BMNH) (det. D. cavus); Cambridge, reared from Galleria mellonella cocoon (A, 1 female) (BMNH) (det. D. cavus); London, reared from Apanteles sp. on larva of Orgyia antiqua (A, 6 females, 6 males) (BMNH) (det. D. cavus); London, reared from Apanteles sp. cocoons on Orgyia antiqua, different from previous (A, 3 females) (BMNH) (det. D. cavus); Cambridge, reared from Galleria mellonella (2 males) (BMNH) (det. D. cavus); Farnham Royal, reared from prob. T. setipennis (host attached, det. R. Peters), bred from nest of blackbird (A, 5 females) (BMNH) (det. Dibrachys sp.); Berkshire, reared from small unidentified Diptera puparium attached to specimen, labeled "reared from Decov nest" (?) (A, 1 female) (BMNH) (det. Dibrachys sp.); Berkshire, no host, reared from nest of wren (A, 2 females) (BMNH) (det. Dibrachys sp.); Hampshire (Hants), reared from Triarthria sp. (A, 7 females, 1 male) (BMNH) (det. Dibrachys sp.); Buckinghamshire (Bucks), reared from pupae of Hofmannophila pseudospretella, Woodroffe material 1961 (A, 15 females, 3 males) (BMNH) (det. Dibrachys sp.); Wiltshire: Malmesbury, reared from puparium of Stenepteryx hirundinis (A, 1 female, 1 male) (BMNH) (det. Dibrachys sp.); Stratford-on-Avon, reared from „? Gelis cocoon ex egg sac of Zygiella x-notata" (1 male) (BMNH) (det. D. cavus); London, no host, labeled Pteromalus lucilla Walker (1 male) (BMNH) (det. D. cavus); Cambridge, reared from sawfly cocoon in old bird nest (4 males) (BMNH) (det. D. cavus); Cambridge, reared from "brown cocoon" (2 males) (BMNH) (det. D. cavus); Enfield, reared from tachinid ex S. salicis (probably Stilpnotia (= Leucoma) salicis) (2 males) (BMNH) (previously unidentified specimen); Farnham Royal, no host, reared from nest of greenfinch (3 males) (BMNH) (det. Dibrachys sp.); British Islands, reared from unidentified tachinid puparium (3 males) (BMNH) (det. Dibrachys sp.); Berkshire: Shillingford, reared from Digonichaeta spinipennis (= Triarthria setipennis) under bark, labeled by Graham "perversus? see type" (1 male) (BMNH) (det. Dibrachys sp.). Eritrea: Asmara, labeled "ex no. 12, epiparasites of Ocinara ficicola (?)" (?, host record unclear; either Ocinara ficicola or epiparasites of Ocinara ficicola are host) (2 of 7 females A) (BMNH) (det. Dibrachys sp.). France: Auxonne, reared from Cotesia glomerata (A, 1 females, 1 male) (BMNH) (det. D. cavus); Lyon, reared from Cotesia glomerata (A, 4 females, 3 males) (BMNH) (det. D. cavus); Lyon, reared from Cotesia glomerata, different collection date than previous with same location and same host species (A, 1 female) (BMNH) (det. D. cavus); Lyon, reared from Cotesia glomerata, different collection date than previous with same location and same host species (1 female) (BMNH) (det. D. cavus); Lyon, reared from Cotesia glomerata, different collection date than previous with same location and same host species (A, 1 female, 1 male) (BMNH) (det. D. cavus); reared from moth in beehive (A, 1 female) (BMNH) (det. D. cavus); reared from moth in beehive, different location than previous (1 male) (BMNH) (det. D. cavus); Vizille, reared from Apanteles liparidis (= Glyptapanteles liparidis) on Lymantria dispar on Populus sp. (A, 3 females, 1 male) (BMNH) (det. D. cavus); Châteauneuf Valais, reared from unidentified tachinid in Archips rosana (2 females, both A) (BMNH) (det. D. cavus); South of France, no host, labeled Pteromalus cavus Walker (3 males) (BMNH) (det. D. cavus). Germany: Schleswig-Holstein: Halstenbek, garden of Langkoppelweg 24, N53.6197 E9.8283 (WGS84), reared from Cotesia glomerata, leg. L. Krogmann 26/04/2006, same data as neotype (2 females, both A (ZMH01-02), 2 males; 2 females in 96 \% EtOH) (ZMH); Hamburg-Bramfeld, Umweltzentrum Karlshöhe, reared from Triarthria setipennis, leg. Peters 22/09/2004 (A, 1 female, 1 male) (ZMH); Hessen: Bad Arolsen, reared from Triarthria setipennis, leg. K. Staiber March 2005 (A, 1 female, 2 males in EtOH) (ZMH); Stock HBM laboratory rearing on Galleria mellonella (A, 2 females, 1 male) (ZMH); Stock HBM laboratory rearing on Calliphora vomitoria (numerous females (26 A) and males, including specimens in Figs 7-9) (ZMH); Berlin, reared from Protocalliphora sp. from tit nest (A, 1 female) (BMNH) (det. D. cavus); Kitzeberg, reared from Pieris sp. (2 of 7 females A, 2 males) (BMNH) (det. D. cavus); Rheinhessen, reared as hyperparasitoid (?) from Aporia crataegi (A, 1 female, 3 males) (BMNH) (det. D. cavus); Berlin, reared from Acronycta aceris (A, 1 female) (BMNH) (det. D. boarmiae); Berlin, reared from Euproctis chrysorrhoea $(1 \mathrm{male})(\mathrm{BMNH})($ det. D. boarmiae); Wangerooge (1 female) (ZMH) (det. $D$. boarmiae); F.S. Elbe I, leg. 14/08/65 (1 prob. female) (ZMH) (det. D. boarmiae); Bavaria: Oberwaiz, leg. 15/07/ 1983, reared from calliphorid puparium (12 females and males, some in bad condition) (ZMH) (det. D. boarmiae); Schleswig-Holstein: Nützen, leg. 01/12/2002, reared from Triarthria setipennis in nest of Passer montanus, 
Voucher specimen Dissertation Lars Krogmann 2005, morphological voucher CH_0044 Krogmann \& Vilhelmsen 2006 (1 female) (ZMH) (det. D. cavus, Krogmann 2003). Hungary: Hortobágy, Ujszentmargita védett erdó, holotype of Tritneptis elegans (A, 1 female) (HNHM). India: Stinagar, reared from Lymantria obfuscata pupa (A, 5 females) (BMNH) (det. D. cavus). Iran: Gilan, reared from Galleria mellonella (A, 3 females, 1 male) (BMNH) (det. D. boarmiae); Kerman, reared from Kermania pistaciella (A, 1 female) (BMNH) (det. D. ? cavus). Italy: Aosta, no host (A, 1 female) (BMNH) (det. D. cavus). Morocco: Middle Atlas, reared from larva (?) of Thaumetopoea pityocampa on Cedrus atlantica (1 female) (BMNH) (det. D. boarmiae). Moldova: Kishinev, reared from Orgyia sp. (3 males) (BMNH) (det. D. cavus). New Zealand: Lincoln, reared from cultured Vespula germanica (A, 2 females, 6 males) (BMNH) (det. D. boarmiae); Christchurch, reared from Vespula germanica (in part cultured) (A, 14 females) (BMNH) (det. D. boarmiae). Pakistan: Mongora, reared from codling moth on apple (prob. Cydia pomonella) (A, 1 female) (BMNH) (det. D. ? cavus by Bouček); Baluchistan (no further location labeled, Baluchistan maybe belonging to Iran), reared from pupa of Cacoecia sp. (A, 2 females) (BMNH) (det. D. boarmiae); Quetta, reared from codling moth on apple (A, 6 females, 1 male) (BMNH) (det. D. ? boarmiae by Bouček); Mingora C.I.B.C., no host, reared from galls on twigs of P. nigra (could be Pinus nigra or Populus nigra) (A, 1 female, 1 male) (BMNH) (det. Dibrachys sp.). Portugal: Central Coast, reared from Pempelia genistella (A, 2 females) (BMNH) (det. D. boarmiae). Serbia: Beograd, no host (A, 1 female) (BMNH) (det. D. cavus); Belgrad, no host (2 females, 1 male) (BMNH) (det. D. cavus). Switzerland: Saxon, reared from Grapholita funebrana (A, 2 females, 2 males) (BMNH) (det. D. cavus); no host (1 female) (BMNH) (det. D. cavus); Nyon, reared from Lobesia botrana (A, 1 female) (BMNH) (det. D. cavus); Simplon, reared from Phytodietus grisianae (A, 2 females, 1 male) (BMNH) (det. D. cavus); Nyon, reared from Grapholita funebrana (1 male) (BMNH) (det. D. cavus); Vaud Commugny, no host, from bird nest (A, 1 female) (NMBE) (det. D. cavus). Syria: Damaskus, reared from Galleria mellonella (A, 2 females, 1 male) (BMNH) (det. D. cavus). Tunesia: Chaffar, reared from Lepidoptera pupa on olive (A, 1 female, 2 males) (BMNH) (previously unidentified specimens). Turkey: Tekirdag, reared from Tenebroides mauritanicus (A, 2 females) (BMNH) (det. D. cavus); Ankara, reared from Galleria mellonella (A, 9 females, 3 males) (BMNH) (det. D. boarmiae); Erzurun, no host, leg. Doganlar 25/06/1981 (1 female) (MDC) (det. $D$. boarmiae); Erzurun, labeled "Apis mellifera" (?, unclear if reared from A. mellifera or from A. mellifera beehive), leg. 18/05/1981 (1 male) (MDC) (det. D. boarmiae); Erzurun, no host, leg. H. Özrek (?) 29/08/1979 (1 female) (MDC) (det. D. cavus); Erzurun, labeled "Prunus mahalep", leg. Doganlar 13/07/1982 (1 female) (MDC) (det. $D$. cavus); Ankara, no host, leg. 15/08/1977 Kiliger (?) (2 females) (MDC) (det. D. boarmiae). USA: Ohio: Columbus, syntype of Arthrolytus apatelae (1 female) (USNM); West Virginia: Morgantown, syntype of Arthrolytus pimplae (1 female) (USNM). No location: B. Cooke Coll. 84-52 (1 female) (BMNH) (det. D. cavus); labeled "aus Plettenberg Zucht 1972, H. Wolf" (6 females, 3 males) (BMNH) (det. D. cavus); reared from nest of Dolichovespula norvegica, leg. C. Nicholson, 1915 (A, 1 female) (BMNH) (det. D. cavus); reared from dipterous puparium under bark, labeled H.W. Miles collection, 1924 (2 females) (BMNH) (det. D. cavus); reared from puparium of Calliphora sp. (2 females, 1 male) (BMNH) (det. D. cavus); lectotype of Pteromalus boarmiae (A, 1 female) (BMNH); paralectotypes of Pteromalus boarmiae Walker (2 females) (BMNH) (det. D. cavus [?]); labeled "leg. Bock 1977" (1 female, 2 males) (ZMH) (det. D. boarmiae); lectotype of Eupelmus cereanus (A, 1 female) (MZUF); paralectotypes of Eupelmus cereanus (2 females, 5 males) (MZUF); syntypes of Cleonymus clisiocampae, labeled "Fitch's Type", "Semiotellus clisiocampae" (A, 1 female, 1 male) (USNM); syntypes of Cheiropachus nigrocyaneus (2 females) (USNM); syntype of Pteromalus chionobae (1 female) (USNM); lectotype of Pteromalus gelechiae (1 male) (INHS); paralectotype of Pteromalus gelechiae, labeled "lectoallotype" (A, 1 female), additional paralectotypes of P. gelechiae (4 females, 4 males) (INHS); labeled "Collectio Ratzeburg [print]", "Pt. Zelleri Psyche ...[illegible; Ratzeburg's hand?]”, "Zelleri R. [hand] det. Ratzeburg [print]”, "Zelleri R. [hand]" (1 male) (NMW) (det. Pteromalus zelleri).

Biology. The long host lists of $D$. cavus and D. boarmiae in such publications as Peck (1963), Krombein et al. (1979) and Noyes (2003) that summarize previously published records are unreliable for delimiting the true host range of D. microgastri for two reasons: (1) the parasitoid and host identifications have not been verified, and (2) earlier authors did not differentiate between D. microgastri and D. lignicola. Table 9 lists 38 verified host species based on label data of specimens we examined where the host species was identified or could be considered a distinct species (e.g., the listed tachinids). Based on this, D. microgastri is a polyphagous species that uses hosts from at least five insect orders, Diptera (3 families of Cyclorrhapha), Lepidoptera (10 families), Hymenoptera (5 families of "Symphyta" and Apocrita), Neuroptera and Coleoptera (one record each). Our list is more reliable, but is 
still extraordinarily long, which shows D. microgastri can parasitize hosts from various orders and is truly polyphagous.

TABLE 9. Hosts of Dibrachys microgastri. Doubtful records from larval hosts are marked with an asterisk (*).

\begin{tabular}{|c|c|}
\hline host species & \\
\hline Tenebroides mauritanicus (Linnaeus) & Coleoptera: Trogossitidae \\
\hline Calliphora sp. & Diptera: Calliphoridae \\
\hline Protocalliphora sp. & Diptera: Calliphoridae \\
\hline Stenepteryx hirundinis (Linnaeus) & Diptera: Hippoboscidae \\
\hline Ocytata pallipes (Fallén) & Diptera: Tachinidae \\
\hline Triarthria setipennis & Diptera: Tachinidae \\
\hline unidentified tachinid from Acronicta psi (Linnaeus) & Diptera: Tachinidae \\
\hline unidentified tachinid from Archips rosana (Linnaeus) & Diptera: Tachinidae \\
\hline unidentified tachinid from Cydia pomonella (Linnaeus) & Diptera: Tachinidae \\
\hline Apanteles longicauda (Wesmael) & Hymenoptera: Braconidae \\
\hline Apanteles solitarius (Ratzeburg) & Hymenoptera: Braconidae \\
\hline Cotesia glomerata (Linnaeus) & Hymenoptera: Braconidae \\
\hline Glyptapanteles liparidis (Bouché) & Hymenoptera: Braconidae \\
\hline Cephus sp. & Hymenoptera: Cephidae \\
\hline Gilpinia hercyniae (Hartig) & Hymenoptera: Diprionidae \\
\hline Gregopimpla inquisitor (Scopoli) & Hymenoptera: Ichneumonidae \\
\hline Phygadeuon sp. & Hymenoptera: Ichneumonidae \\
\hline Phytodietus griseanae (Kerrich) & Hymenoptera: Ichneumonidae \\
\hline Vespula germanica (Fabricius) & Hymenoptera: Vespidae \\
\hline Tyria jacobaeae (Linnaeus)* & Lepidoptera: Arctiidae \\
\hline Eutromula pariana (Clerck) & Lepidoptera: Choreutidae \\
\hline Coleophora sp. & Lepidoptera: Coleophoridae \\
\hline Pectinophora gossypiella (Saunders) & Lepidoptera: Gelechiidae \\
\hline Euproctis chrysorrhoea (Linnaeus) & Lepidoptera: Lymantriidae \\
\hline Lymantria obfuscata Walker & Lepidoptera: Lymantriidae \\
\hline Orgyia antiqua (Linnaeus) & Lepidoptera: Lymantriidae \\
\hline Acronicta aceris (Linnaeus) & Lepidoptera: Noctuidae \\
\hline Oeneis semidea Say & Lepidoptera: Nymphalidae \\
\hline Hofmannophila pseudospretella (Stainton) & Lepidoptera: Oecophoridae \\
\hline Pieris sp. & Lepidoptera: Pieridae \\
\hline Galleria mellonella & Lepidoptera: Pyralidae \\
\hline Pempelia genistella (Duponchel) & Lepidoptera: Pyralidae \\
\hline Thaumetopoea pityocampa (Denis \& Schiffermüller)* & Lepidoptera: Thaumetopoeidae \\
\hline Kermania pistaciella Amsel & Lepidoptera: Tineidae \\
\hline Cacoecia sp. & Lepidoptera: Tortricidae \\
\hline Cydia pomonella (Linnaeus) & Lepidoptera: Tortricidae \\
\hline Grapholita funebrana (Treitschke) & Lepidoptera: Tortricidae \\
\hline Grapholita molesta (Busck) & Lepidoptera: Tortricidae \\
\hline Lobesia botrana (Denis \& Schiffermüller) & Lepidoptera: Tortricidae \\
\hline Wesmaelius subnebulosus (Stephens) & Neuroptera: Hemerobiidae \\
\hline
\end{tabular}


Only pupal stages of hosts appear to be used by $D$. microgastri, which implies they are restricted to holometabolous insects. Gontarski (1939) reported the use of cocooned Lepidoptera larvae, which are immobile, but this record is doubtful. Some museum material of D. microgastri was labeled with host records from Lepidoptera larvae, including Tyria jacobaeae (Arctiidae) and Thaumetopoea pityocampa (Thaumetopoeidae). These records are probably wrong or based on unrecognized hyperparasitism of Ichneumonoidea pupae on the lepidopteran larvae and therefore are marked as doubtful in the host list (Table 9).

D. microgastri is a facultative hyperparasitoid through parasitic Hymenoptera and Diptera. Facultative secondary hyperparasitism is common in ectoparasitic parasitoids (Askew \& Shaw 1986). The record of parasitism of an Ichneumonidae pupa inside the puparium of the tachinid T. setipennis also demonstrates facultative tertiary parasitism for D. microgastri. Gordh (1981) stated that tertiary parasitism is always facultative.

Polyphagy of D. microgastri is also supported by our laboratory rearings on different species of Calliphoridae (Diptera) and on Galleria mellonella (Lepidoptera: Pyralidae), using parasitoids from a stock originally reared from tachinid puparia (Peters 2007). Although successful rearing in the lab can give information about a parasitoid's potential ability to use a host, this has to be considered with caution because it is known that parasitoids can use hosts that are normally outside their host range if no natural hosts are available and an artificial situation is created in a Petri dish (Godfray 1994). Accordingly, we only listed field host records in Table 9.

Distribution. Dibrachys microgastri is a cosmopolitan species. Noyes (2003) listed 57 countries for distribution. Those countries we confirmed or added through our examination of specimens are listed in Table 10.

TABLE 10. Geographic distribution of Dibrachys microgastri.

\begin{tabular}{llll}
\hline geographic region & country & geographic region & country \\
\hline Europe & Bulgaria & Asia & Afghanistan \\
Croatia & & Cyprus \\
Czech Republic & & India \\
& France & & Iran \\
Germany & & Pakistan \\
& Hungary & & Syria \\
& Italy & Africa & Algeria \\
& Moldova & & Egypt \\
& Portugal & & Eritrea \\
& Serbia & & Morocco \\
Switzerland & & Tunesia \\
Europa/Asia & England & North America & Canada \\
& Turkey & & USA \\
& & Australia & \\
\hline
\end{tabular}

Taxonomic remarks. After morphological examination of females and males, morphometric analysis, and examination of name-bearing types, we consider D. cavus, D. boarmiae and $D$. clisiocampae to be synonyms. Dibrachys cavus and D. boarmiae have always been considered close (Graham 1969, Sharkov 1982) and their synonymy was said to be likely but was not formally stated by Zerova et al. (1986). Dibrachys clisiocampae was synonymized with $D$. cavus by Gahan (1938) but was re-established by Doganlar (1987).

Our analyses show the characters used to separate these three putative species are not reliable, including the three characters of the hypopygium used by Doganlar (1987) (Table 8). The other characters mentioned by Doganlar (1987) and Graham (1969) to separate D. cavus and D. boarmiae also proved to be intraspecifically variable. These characters were: "head breadth to length", "eye height to breadth", "eye margin emarginate or not" and the expression of the male gastral spot. Further characters such as the weakly colored discal cloud on the forewing in D. boarmiae was not observed in any specimen, and the shape of the wing stigma and differences in color are considered unsuitable for making taxonomic inferences (see Discussion). 
We consider the senior synonym of D. cavus, D. boarmiae and D. clisiocampae to be Dibrachys microgastri (Bouché, 1834), which was originally described as Diplolepis microgastri but assigned to Dibrachys and listed as a possible synonym of D. cavus by Graham (1969). Vidal (2001) and Noyes (2003) listed the name as valid because Graham (1969) did not formally synonymize it. The original description includes a host record from Cotesia glomerata (= Apanteles glomeratus, Microgaster glomeratus) (Hymenoptera: Braconidae). Cotesia glomerata and other braconid species are commonly recorded host species for D. cavus (Noyes 2003; see also examined material and Table 9). Known hosts of $D$. verovesparum do not include Braconidae and although there is a single record of an Apanteles Förster (Braconidae) parasitoid of D. lignicola (see below), these species cannot be what Bouché (1834) described as $D$. microgastri because the original description states that the male is "stahlblau angelaufen" (tarnished steel-blue) which does not apply to either D. verovesparum or D. lignicola. The type material of $D$. microgastri is presumed lost (Graham 1969) and in order to resolve present nomenclatural instability we designate a neotype female for D. microgastri. The neotype was selected from the same host species, Cotesia glomerata, and the same geographic region, Northern Germany, as the type material used by Bouché (1834) in establishing Diplolepis microgastri. Although the name D. cavus has been widely used for almost a century, we deliberately refrain from requesting the International Commission on Zoological Nomenclature to set aside the lesser known name D. microgastri because $D$. cavus has often been confused with different species of Dibrachys, most notably D. lignicola and D. braconidis, and $D$. cavus as used in the literature has a highly ambiguous meaning. The adoption of D. microgastri thus underpins the changes associated with our redefinition of the species.

Dibrachys elegans is another new synonym of D. microgastri. The description of Tritneptis elegans by Szelényi (1981) contains a number of mistakes and ambiguous statements, which cause confusion or do not correspond to the holotype or the genus Dibrachys (e.g., funicle is used for flagellum, and "without any sign of notaulices", "scutellum a little shorter than mesoscutum (1.0:1.9)", and "ovipositor as long as a third of hind tibia" are stated). However, other parts of the description clearly show that this refers to the specimen that was examined by us as the holotype female. From our morphological examination and morphometric analysis there is no doubt that it is a female of D. microgastri.

In addition to the above synonymy, we confirmed all recorded synonyms of $D$. cavus and $D$. clisiocampae as synonyms of $D$. microgastri after examination of accessible type material. In the following we provide further information on these synonyms.

The type material of all of Ratzeburg's taxa unfortunately is presumed lost. We examined a male (NMW) labeled "Collectio Ratzeburg" and "Pt. Zelleri Psyche ..." [illegible]. The latter is possibly written in Ratzeburg's hand. Pteromalus zelleri Ratzeburg, 1848 was described based on a female reared from Bombyx neustria (Linnaeus) (= Malacosoma neustria) (Lepidoptera: Lasiocampidae). We therefore conclude that this male reared from Psyche sp. is not a type specimen of $D$. zelleri, though it probably is from Ratzeburg's collection.

Despite the remarks of Novitzky in Graham (1969: 810), we follow the conclusions of Kurdjumov (1913) who stated that $D$. vesparum (Ratzeburg, 1852) is a synonym of $D$. boucheanus and hence a synonym of $D$. microgastri. Kurdjumov (1913) reported that he examined the then still existing type material of Ratzeburg. Graham (1969: 810) mentioned some specimens he received from Z. Bouček that were reared from Dolichovespula saxonica (Fabricius) (Hymenoptera: Vespidae) and that he suspected might be "the true vesparum". We include these specimens in the type material of our new species $D$. verovesparum and do not consider they are conspecific with $D$. vesparum because the original description of the latter states: (1) gaster as long as head and mesosoma, and (2) body "ölgrün" (oilgreen). A black body without green metallic coloration and a short gaster (always shorter than head plus mesosoma) are two diagnostic characters of our new species and we thus consider $D$. vesparum as a synonym of $D$. microgastri. Vespidae are not only hosts of our new species, but are also within the confirmed host range of $D$. microgastri (Table 9), which supports our conclusion.

The original description of Cheiropachus nigrocyaneus Norton, 1869 states " 3 specimens bred". The examined 2 specimens are in bad condition (e.g., heads missing), which makes species assignment difficult though they clearly belong to Dibrachys. Because this name was already synonymized with D. clisiocampae by Girault (1916b: 408) and with $D$. cavus by Gahan (1938: 211) we consider it a synonym of D. microgastri.

We examined the lectotype male and paralectotypes (one female labeled "lectoallotype" and 4 females and 4 males labeled paratypes) of Pteromalus gelechiae Webster, 1883. There is no doubt about the synonymic status of this species. 
The original description of Pteromalus chionobae Howard, 1889 states that it was based on 2 specimens reared from Oeneis semidea (Lepidoptera: Nymphalidae). The single examined female syntype is in bad condition (without head and gaster separated), but it can be assigned to D. microgastri with high certainty.

We examined a syntype of Arthrolytus apatelae Ashmead, 1893 that again is in very bad condition (head, gaster and forewings missing). From our examination of the remaining mesosoma it can be assigned to Dibrachys, but not to species. However, we consider A. apatelae a synonym of D. microgastri based on Girault (1916a; 1916b) and Gahan (1938).

One female syntype of Arthrolytus pimplae Ashmead, 1894 was examined. It was reared from Pimpla inquisi$\operatorname{tor}$ (= Gregopimpla inquisitor) (Ichneumonidae) and we base this host record for D. microgastri on this specimen.

In addition to the above synonymy, Graham (1956) transferred Pteromalus perversus Walker, 1835 to Dibrachys and subsequently listed it as a questionable synonym of D. cavus (Graham 1969) based on one male from the Walker collection that he considered was the type (probably holotype). Walker (1835) had erroneously described this male as a female in the original description. Unfortunately, we were unable to locate this specimen in the BMNH or elsewhere (e.g., HDOU). We did examine a male labeled "perversus? see type" by Graham (BMNH), which Graham (1969: 811) stated was "extremely close" to the probable holotype of D. perversus. This is a male of $D$. microgastri and suggests that the missing holotype male of $D$. perversus was also a specimen of $D$. microgastri. However, the original description by Walker (1835) does not provide any useful information further to the brief notes given by Graham (1969). Graham (1969) did not formally synonymize $D$. perversus with $D$. cavus and because we could not locate the probable male holotype of $D$. perversus we prefer to treat the name as valid, but as a nomen dubium in our list of valid species (see Appendix).

\section{Dibrachys lignicola Graham, 1969}

(Figs 7b, 7e, 8b, 8e, 9b, 9e)

Dibrachys (Dibrachys) lignicola Graham, 1969: 810, holotype female in HDOU (Type HYM: 1283) (examined by Peters). Dibrachys (Dibrachys) goettingenus Doganlar, 1987: 202-203, holotype female in IFUG (examined by Peters); syn. n.

Diagnosis. Both sexes. Eyes large, eye height greater than 2.0x POL. Head and mesosoma with distinct metallic coloration (Figs 7b, 7e, 8b, 9b).

Female. Gaster short and eyes broad, gaster length equal to or less than 4.05x eye breadth (Figs 6, 7b, Table 7) and shorter than head plus mesosoma. Eyes broad and oval, eye height equal to or less than 1.6x eye breadth, outer margin never distinctly emarginate (Fig. 7b). Stigmal vein long compared to marginal vein, marginal vein mostly less than 2.0x stigmal vein (1.57-2.05, but only 2 of $47>2.0$ ) (Fig. 8e). Mesoscutum never bluish. Mouth narrow, head breadth greater than $2.0 \mathrm{x}$ mouth breadth (Fig. 7e).

Male. Scape and pedicel apically with distinct lobe on outer side (Fig. 9e). Gastral spot distinct (Fig. 9b).

Description. FEMALE (Figs 7b, 7e, 8b, 8e). Body length 2000-3000 $\mu \mathrm{m}$.

Head (Figs 7b, 7e). Eyes large and usually oval, with outer margin rarely only very slightly emarginate; eye 1.38-1.60x as high as broad; eye height 2.11-2.68x POL. Level of lower margin of antennal toruli at level of lower ocular line. Clypeus distinctly striate vertically, though less distinct towards lower margin. Lower face only moderately receding. Mouth narrow, head breadth $2.10-2.55 x$ mouth breadth; mouth breadth $2.38-2.92 x$ malar space. POL 1.55-2.11x OOL. First anellus ringlike, second anellus slightly longer than broad; first funicular segment slightly longer than broad, second to fifth quadrate, and sixth slightly transverse; flagellum $0.63-0.77 \mathrm{x}$ head breadth.

Mesosoma (Fig. 8b). Mesoscutum and scutellum slightly convex in lateral view. Mesoscutum $0.51-0.61 \mathrm{x}$ as long as broad. Reticulation coarse, slightly coarser than in D. microgastri, 10.7-14.9 meshes/200 $\mu \mathrm{m}$ in anterior part of mesoscutum. Marginal rim of scutellum only moderately turned upwards. Plicae straight or weakly curved; median carina weak or interrupted.

Wings (Fig. 8e). Wings hyaline; stigmal vein long, marginal vein only $1.57-2.05 \mathrm{x}$ stigmal vein; submarginal vein $1.74-2.24 \mathrm{x}$ marginal vein.

Metasoma (Fig. 7b). Gaster shorter than head plus mesosoma; massive and broad, moderately pointed; length 3.54-4.05x eye breadth. Tergites smooth, weakly alutaceous and with some strong hairs in apical half of gaster.

Color (Figs 7b, 7e, 8b). Head with distinct metallic coloration, usually dark green. Antenna varying from brown to dark brown, in general slightly darker than in D. microgastri. Mesosoma with distinct metallic coloration, 
but never blue or almost black, mostly with distinct tinge of bronze or gold, especially on scutellum; ventral surface black with tinge of blue. Venation of wings light brown. Coxae concolorous with mesosoma. Trochanters, femora and tibiae usually yellow or light brown, rarely brown, generally lighter than in D. microgastri. Tarsi yellow, last two segments of metatarsus sometimes darker. Gaster brown to dark brown, shiny.

MALE (Figs 9b, 9e). Similar to female except as follows. Smaller, body length 1500-2000 $\mu$ m.

Head. Eye height 2.19-2.62x POL. Scape and pedicel apically with distinct lobe on outer side (Fig. 9e).

Color (Fig. 9b). Mesoscutum and scutellum always distinctly metallic green or dark green, rarely with a slight tinge of blue; bronze on scutellum mostly indistinct. Coxae dark brown, sometimes at least in part concolorous with mesosoma. Gaster with distinct light testaceous spot on ventral side of anterior segments, the spot also visible in dorsal view.

Material examined. England: Berkshire, Slough, reared from Crataerina pallida pupae by Woodroffe 1951 (A, 5 females) (BMNH) (det. Dibrachys sp.); Farnham, reared from Diptera puparium (A, 2 females) (BMNH) (det. D. cavus); Hampshire (Hants), reared from dead Larix trunk (A, 5 females, 2 males) (BMNH) (det. D. boarmiae). France: Sollies Pont, reared from pupae of Cydia pomonella (A, 2 females, 1 male) (BMNH) (det. D. cavus). Germany: Hamburg, reared from puparia of Triarthria setipennis, leg. R. Peters March 2006 (6 of numerous females A, and numerous males) (ZMH); Hamburg, stock HRL, laboratory rearing on Calliphora vomitoria (20 of numerous females A, and numerous males) (ZMH); Hamburg, reared from Ocytata pallipes, leg. R. Peters (numerous females and males) (ZMH); Hamburg, stock HRL II (numerous females and males, including specimens in Figs 7-9); Hessen: Bad Arolsen, host Ornithomya avicularia, leg. K. Staiber March 2005 (2 females, 1 male, all dead inside host puparium) (ZMH); Göttingen, reared from Gilpinia hercyniae, holotype of Dibrachys goettingenus (A, 1 female) (IFUG); paratypes of D. goettingenus, same data as holotype (all 3 females A, 1 male) (IFUG); paratypes of D. goettingenus, same data as holotype (A, 2 females) (BMNH). Ireland: Dublin, Harold's Cross, 22.viii.1954, on a wooden post in garden at 14, Clareville Road, holotype of Dibrachys lignicola (1 female A) (HDOU); paratypes of Dibrachys lignicola, same data as holotype (all 5 females A, 1 male) (BMNH); Dublin, Harold's Cross, paratype of D. lignicola, in house (A, 1 female) (BMNH). Italy: Tuscany, reared from Phryxe caudata on Thaumetopoea pityocampa (A, 8 females, 1 male) (BMNH) (det. Dibrachys sp.); Conca del Re Castrovillari, NP of Pollino, reared from Phryxe caudata associated with Thaumetopoea pityocampa (1 female) (ZMH). Morocco: Mamora, reared from Apanteles sp. on Lymantria dispar (2 females, 1 male) (BMNH) (det. D. cavus). Switzerland: Vaud Bonvillars, ex bird nest (A, 2 females) (NMBE) (det. D. cf. goettingenus). USA: California, Riverside, reared from tachinid puparium (A, 6 females, 5 males) (BMNH) (det. D. cavus). (Former) Yugoslavia: no host (1 female) (BMNH) (det. D. cavus).

Biology. Noyes (2003) listed only a single lepidopteran host record for D. lignicola, though also one hymenopteran species for D. goettingenus based on Doganlar (1987). Our study shows D. lignicola uses pupae of Diptera (Tachinidae, Hippoboscidae) in addition to Hymenoptera (Diprionidae, Braconidae) and Lepidoptera (Tortricidae) (Table 11). We added to the records in Noyes (2003) several other countries that are in the range of distribution of D. lignicola (Table 11). The record from North America (USA) is a single record and needs confirmation. There are only two records from Africa (Algeria (Noyes 2003), Morocco). The Moroccan record from Apanteles sp. cocoons is extraordinary because it is the only record from parasitic Hymenoptera, though we frequently found this species in the puparia of two earwig parasitoids (Diptera: Tachinidae) (Table 11). The recorded host species show no obvious similarities, but the revised taxonomy and key to species might help to identify further aspects of this species' biology in the future.

Distribution. See Table 11 for confirmed records.

Taxonomic remarks. The establishment of D. goettingenus by Doganlar (1987) was most probably made only because the description of D. lignicola by Graham (1969) is incomplete. Graham only mentioned the lobe on the scape in males and makes no statement about a lobe on the pedicel. Doganlar used the lobe on both the scape and pedicel as the main diagnostic character for his D. goettingenus. Doganlar was unable to check the character for $D$. lignicola males because Graham's collection was not accessible to him. It is now part of the NHM collection and we examined the type series of $D$. lignicola, which showed that male paratypes have a distinct lobe on both the scape and pedicel. Further differences mentioned by Doganlar (1987: 203) to distinguish the two species proved unreliable. The ratio of eye height to eye breadth in females varies more strongly than indicated by Doganlar and also the difference in the POL to OOL ratio was not confirmed.

Though males of Dibrachys lignicola and D. microgastri are easily distinguished by the structure of the scape and pedicel, females are difficult to differentiate. The diagnostic characters used by Graham (1969) and Doganlar 
(1987) to separate the females of the two groups, the ratios of eye height to breadth, mouth breadth to malar space, and gaster length to length of head plus mesosoma, proved to overlap in our morphometric analysis. The separation of D. lignicola and D. microgastri females is only possible using the characters given in our key (see also Fig. 6 and Table 7), though there is still no single character known to completely separate females of the two species. If the identification is in doubt one should simply try another specimen of these gregarious parasitoids, if accessible.

TABLE 11. Hosts and geographic distribution of Dibrachys lignicola.

\begin{tabular}{lll}
\hline country & host species & \\
\hline Germany & $\begin{array}{l}\text { Triarthria setipennis } \\
\text { Ocytata pallipes } \\
\text { Ornithomya avicularia } \\
\text { Gilpinia hercyniae } \\
\text { Cydia pomonella }\end{array}$ & $\begin{array}{l}\text { Diptera: Tachinidae } \\
\text { Diptera: Tachinidae }\end{array}$ \\
Diptera: Hippoboscidae \\
France & Phryxe caudata & $\begin{array}{l}\text { Hymenoptera: Diprionidae } \\
\text { Italy }\end{array}$ \\
Switzerland & Lepidoptera: Tortricidae \\
former Yugoslavia & Diptera: Tachinidae \\
England & Crataerina pallida & \\
Ireland & Diptera: Hippoboscidae \\
Morocco & Apanteles sp. & \\
USA (California) & Tachinidae sp. & Hymenoptera: Braconidae \\
\hline
\end{tabular}

\section{Dibrachys verovesparum Peters \& Baur sp. $\mathbf{n}$.}

(Figs 7c, 7f, 8c, 8f, 9c, 9f)

Diagnosis. Both sexes. Eyes small, eye height equal or less than 2.0x POL (Figs 7c, 9c). Head and mesosoma black without metallic coloration or only with slight tinge of bronze, brown or green (Figs 7c, 7f, 8c, 9c, 9f).

Female. Gaster shorter than head plus mesosoma (Fig. 7c). Eyes oval, eye height less than 1.6x eye breadth, outer margin never distinctly emarginate (Fig. 7c). Mouth broad, head breadth equal to or less than 2.0x mouth breadth (Fig. 7f).

Male. Scape and pedicel apically without lobe on outer side (Fig. 9f). Gastral spot distinct (Fig. 9c).

Description. FEMALE (Figs 7c [holotype], 7f, 8c, 8f [paratype no. 15]). Body length 1780-2650 $\mu \mathrm{m}$.

Head (Figs 7c, 7f). Eyes small and oval, outer margin not emarginate; eye 1.32-1.57x as high as broad; eye height 1.69-2.00x POL. Level of lower margin of antennal toruli at level of lower ocular line. Clypeus striate vertically, indistinctly reticulate in its median part. Lower face distinctly receding. Mouth broad, head breadth 1.75$2.00 x$ mouth breadth; mouth breadth 2.47-3.04x malar space. POL 1.71-2.20x OOL. First anellus small and ringlike, second anellus distinctly transverse rectangular, $1.5 \mathrm{x}$ broader than long; first funicular segment longer than broad, second to sixth almost quadrate; flagellum $0.68-0.77 \mathrm{x}$ head breadth.

Mesosoma (Fig. 8c). Mesoscutum flat, scutellum slightly convex in lateral view. Mesoscutum 0.51-0.60x as long as broad. Reticulation of pronotal collar, mesoscutum, scutellum and frenum fine, 13.1-17.0 meshes/200 $\mu \mathrm{m}$ in anterior part of mesoscutum. Marginal rim of scutellum distinctly turned upwards. Plicae distinct, weakly curved; median carina distinct or interrupted.

Wings (Fig. 8f). Wings hyaline; marginal vein 1.43-2.07x stigmal vein; submarginal vein $2.06-2.37 \mathrm{x}$ marginal vein.

Metasoma (Fig. 7c). Gaster shorter than head plus mesosoma; broad, oval and not distinctly pointed; length 3.50-4.61x eye breadth. Tergites not very smooth and not very shiny, weakly alutaceous, especially in apical half of gaster and with few, but distinct and strong hairs; sternites without hairs.

Color (Figs 7c, 7f, 8c, 8f). Head and mesosoma black, without metallic coloration, sometimes with slight tinge of brown or bronze on face, vertex, mesoscutum, scutellum and axillae. Antennal segments varying from light brown to brown, flagellum usually slightly darker than scape and pedicel. Venation of wings usually pale brownish. 
Legs light brown, metafemur brown; coxae brown, proximal parts sometimes concolorous with mesosoma. Gaster dark brown.

MALE (Figs 9c, 9f [paratype no. 11A]). Similar to female except as follows. Smaller, body length 1340-2050 $\mu \mathrm{m}$.

Head. Eye height 1.55-1.92x POL. Level of lower margin of antennal toruli slightly above lower ocular line. Scape and pedicel apically without lobe on outer side.

Metasoma (Fig. 9c). Gaster almost circular.

Color (Figs 9c, 9f). Head black or sometimes with tinge of bronze and green a little more distinct than in females. Antennae usually completely light brown. Gaster with distinct light testaceous spot on ventral side of anterior segments, the spot also visible in dorsal view.

Material examined. Holotype female. Germany: Schwarzwald, Eschbach, reared from Dolichovespula saxonica, labeled leg. R. Gauss, leg. 3.ii. 1966, ex Dolichovespula saxonica det. R. Gauss, Dibrachys sp. [prope vesparum (Ratz.)] Zd. Bouček 1968; det. R. Peters 2009. Deposited at SMNS.

Paratypes. Austria: S.E. Styria, coll. 30.v.82 CIBC, ex Sphecophaga vesparum in V. saxonica, labeled Dibrachys (?) vesparum (Ratz.) det. Z. Bouček, 1984 (7 females (NHM no. 1-7)) (BHNH). England: London, no host, labeled Syn. Pteromalus vitripennis, det. Bouček 1977, paralectotype of D. boarmiae (1 female) (BMNH) (det. D. boarmiae, transferred to D. verovesparum). Germany: all specimens from Schwarzwald, Eschbach; coll. 2.ii.1966, ex Dolichovespula saxonica (P.) det. R. Gauss, labeled M.W.R. de V. Graham coll. BMNH (E) 1995-489 (1 female (NHM no. 8), 1 male) (BMNH); leg. 4.ii.1966, ex Dolichovespula saxonica det. R. Gauss, Dibrachys sp. [prope vesparum (Ratz.)] Zd. Bouček 1968 (1 female) (SMNS); leg. 7.ii.1966, ex Sphecophaga vesparum Curt. det. R. Gauss, Dibrachys vesparum (Ratz.) det. R. Gauss (3 females, 3 males, including paratype no. 11A) (SMNS); leg. 7.ii.1966, ex Sphecophaga vesparum Curt. det. R. Gauss, Dibrachys spec. nahe vesparum (Rtzb.) det. Z. Bouček (8 females, 2 males, including paratype no. 15) (SMNS); leg. 21.ii.1966, ex Sphecophaga vesparum Curt. det. R. Gauss, Dibrachys sp. [prop. vesparum (Ratz.)] Zd. Bouček 1968 (3 females, 3 males [1 female, 1 male in SMNS; 1 female, 1 male in NMBE; 1 female, 1 male in ZMH]); ex Sphecophaga vesparum Curt. det. R. Gauss, Dibrachys vesparum (Ratz.) det. R. Gauss (4 females, 4 males) (SMNS); ex Sphecophaga vesparum Curt. det. R. Gauss, Dibrachys vesparum (Ratz.) det. Z. Bouček (1 female [paratype 12, not used for morphometric analysis], 1 male) (SMNS).

Biology. The host species of D. verovesparum are Dolichovespula saxonica (Hymenoptera: Vespidae) and Sphecophaga vesparum (Curtis) (Hymenoptera: Ichneumonidae), a primary parasitoid of Vespidae. Further collection of vespid nests is necessary to increase our knowledge on life history of this species.

Distribution. Europe. Germany, Black Forest; Austria, Styria; England.

Etymology. From the Latin verus, meaning "true", and vesparum; referring to the material in Graham (1969: 810) that he considered might be the "true" D. vesparum, which we interpret as a new species (see under "Taxonomic remarks" for D. microgastri).

Taxonomic remarks. Our interpretation of the name D. vesparum, which was described originally from females reared from a wasp nest, is discussed under D. microgastri. Based on the original description we do not think $D$. vesparum is conspecific with our new species.

\section{Discussion}

The results of this study can provide information to refine the selection of characters for taxonomic analysis of other Pteromalidae. Qualitative characters often include the color of weakly sclerotized body parts like antennae, eyes, legs and gaster (e.g., Graham 1969). We consider these too variable, being influenced by body size, age, host, and preservation medium, and thus they should not be used for species identification. An exception is the color of the head and mesosoma, which are highly sclerotized. The coloration of these was found to be consistent and could be used as a diagnostic character, which is why we used it in the diagnosis of D. verovesparum.

Another example of a variable character is the shape of the stigma of the forewing. Shape of the stigma can not only vary in one species, but can even be different between the two forewings (Baur, unpublished) and thus is an unsuitable character for taxonomic inferences. This is also true for a number of morphometric characters that have been used before. Measurements taken of such characters as head length or temple length (Graham 1969, Doganlar 
1987) vary decisively with only slight changes of position. These characters were not used in this study and should be avoided in future studies. Overall size differences may also not be used to separate parasitoid species because of differences in host size and quality or in the degree of superparasitism. Intraspecific differences in size are a typical phenomenon in parasitoids and especially in idiobionts like most Pteromalidae (Godfray 1994).

\section{Acknowledgements}

For loans, information and giving access to material the authors thank Luca Bartolozzi, Zoological Museum "La Specola”, University of Florence (Italy); Gavin Broad, Natalie Dale-Skey Papilloud, John Noyes, Andrew Polaszak and Suzanne Ryder, The Natural History Museum, London (UK); Miktat Doganlar, Mustafa Kemal University, Antakya-Hatay (Turkey); Michael Gates, United States Museum of Natural History, Washington D.C. (USA); Lars Krogmann, Staatliches Museum für Naturkunde Stuttgart, Stuttgart (Germany); Darren Mann and James Hogan, Hope Department, Oxford University, Oxford (UK); Stefan Schmidt, Zoologische Staatssammlung München, Munich (Germany); Stefan Schütz and Julian Heiermann, Institut für Forstzoologie der Universität Göttingen, Goettingen (Germany); Paul Tinerella, Illinois Natural History Survey, Urbana, Illinois (USA); Dominique Zimmermann, Naturhistorisches Museum Wien, Vienna (Austria); and László Zoltán, Hungarian Natural History Museum, Budapest (Hungary). We acknowledge Karl Staiber (Bad Arolsen) and Jörg Roloff (Nützen) for collecting bird nests from which Dibrachys spp. were reared. SYNTHESYS funded the stay of RSP at the NHM. Furthermore, we thank Gary Gibson, two anonymous reviewers, and Elsa Obrecht (Bern) for useful comments on the manuscript, and Rudolf Abraham (Hamburg) for starting the studies on life history and taxonomy of Dibrachys.

\section{References}

Anderson, T.W. (2003) An introduction to multivariate statistical analysis. Wiley, New York, 752 pp.

Ashmead, W.H. (1888) On the chalcideous tribe Chiropachides. Canadian Entomologist, 20 (9), 172-176.

Ashmead, W.H. (1893) Descriptions of new parasitic Hymenoptera bred by Prof. F.M. Webster. Bulletin of the Ohio Agricultural Experiment Station, Technical Series, 1, 159-165.

Ashmead, W.H. (1894) Descriptions of new parasitic Hymenoptera. Transactions of the American Entomological Society, 21, 318-344.

Askew, R.R. \& Shaw, M.R. (1986) Parasitoid communities: their size, structure and development. In: Waage, J. \& Greathead, D. (Eds.), Insect parasitoids. Academic Press, London, pp. 225-264.

Baur, H. (2002) The power of multivariate statistical methods in the taxonomy of Pteromalidae (Hymenoptera: Chalcidoidea). In: Melika, G. \& Thuroczy, C. (Eds.), Parasitic wasps: Evolution, systematics, biodiversity and biological control. Agroinform, Budapest, pp. 73-81.

Blanchard, E.E. (1938) Un nuevo enemigo de la oruga del duraznero. Revista Chilena de Historia Natural, 41, 178-180.

Bouček, Z. (1965) A review of the Chalcidoid fauna of the Moldavian S.S.R. with descriptions of new species (Hymenoptera). Acta Faunistica Entomologica Musei Nationalis Pragae, 11, 5-38.

Bouček, Z. (1974) On the Chalcidoidea (Hymenoptera) described by C. Rondani. Redia, 55, 241-285.

Bouček, Z. \& Heydon, S.L. (1997) Chapter 17. Pteromalidae. In: Gibson, G.A.P., Huber, J.T. \& Woolley, J.B. (Eds.), Annotated keys to the genera of Nearctic Chalcidoidea (Hymenoptera). NRC Research Press, Ottawa, pp. 541-692.

Bouček, Z. \& Rasplus, J.-Y. (1991) Illustrated key to West-Palearctic genera of Pteromalidae (Hymenoptera: Chalcidoidea). Institut National de la Recherche Agronomique, Paris, 140 pp.

Bouché, P.F. (1834) Naturgeschichte der Insekten, besonders in Hinsicht ihrer ersten Zustände als Larven und Puppen. Berlin, $216 \mathrm{pp}$.

Claude, J. (2008) Morphometrics with R. Springer, New York, 318 pp.

Delucchi, V. (1955) Notes sur les ptéromalides. Mémoires de la Société Royale Entomologique de Belgique, 27, $171-175$.

Doganlar, M. (1987) Hypopygia of most Nearctic and Palearctic species of Dibrachys Foerster, key to most species of the genus, and descriptions of three new species (Hymenoptera, Pteromalidae). Spixiana, 10, 191-206.

Fitch, A. (1856) Report on the noxious, beneficial and other insects. Transactions of the New York State Agricultural Society, $15,409-459$.

Förster, A. (1856) Hymenopterologische Studien. 2. Chalcidiae und Proctotrupii. Aachen, 152 pp.

Frison, T.H. (1927) List of the insect types in the collections of the Illinois State Natural History Survey and the University of Illinois. Bulletin of the Illinois State Laboratory of Natural History, 16, 137-309.

Gahan, A.B. (1938) Notes on some genera and species of Chalcidoidea (Hymenoptera). Proceedings of the Entomological Society of Washington, 40, 209-227. 
Gahan, A.B. (1942) Descriptions of five new species of Chalcidoidea, with notes on a few described species (Hymenoptera). Proceedings of the United States National Museum, 92, 41-51.

Gibson, G.A.P. (1997) Morphology and terminology. In: Gibson, G.A.P., Huber, J.T. \& Woolley, J.B. (Eds.), Annotated keys to the genera of Nearctic Chalcidoidea (Hymenoptera). NRC Research Press, Ottawa, pp. 16-44.

Girault, A.A. (1916a) New miscellaneous chalcidoid Hymenoptera with notes on described species. Annals of the Entomological Society of America, 9 (3), pp. 291-308.

Girault, A.A. (1916b) The North American Species of Dibrachys (in the North American Sense - Coelopisthoidea Gahan) with a note on Uriella Ashmead. The Canadian Entomologist, 48, 408-409.

Godfray, H.C.J. (1994) Parasitoids - Behavioural and evolutionary ecology. Princeton University Press, Princeton, New Jersey, $488 \mathrm{pp}$.

Gontarski, H. (1939) Zur Biologie der Schlupfwespe Dibrachys cavus (Walk.). Zeitschrift für Morphologie und Ökologie der Tiere, 35, 203-220.

Gordh, G. (1981) The phenomenon of insect hyperparasitism and its taxonomic occurrence in the Insecta. In: Rosen, D. (Ed.), The role of hyperparasitism in biological control: A Symposium. University of California Division of Agricultural Science, pp. 10-18.

Graham, M.W.R.d.V. (1956) A revision of the Walker types of Pteromalidae (Hym., Chalcidoidea). Part 2 (including descriptions of new genera and species). Entomologist's Monthly Magazine, 92, 246-263.

Graham, M.W.R.d.V. (1969) The Pteromalidae of North-Western Europe (Hymenoptera, Chalcidoidea). Bulletin of the British Museum (Natural History). Entomology, Supplement, 16, 1-908.

Howard, L.O. (1889) The Hymenopterous parasites of North American Butterflies including a section upon the miscogasters by C.V. Riley. In: Scudder, S.H. (Ed.), The Butterflies of the Eastern United States and Canada, with special reference to New England. Cambridge, Massachusetts, USA, pp. 1869-1911.

Janzon, L.-A. (1986) Morphometric studies of some Pteromalus Swederus species (Hymenoptera: Chalcidoidea) with emphasis on allometric relationships, or: Are ratios reliable in chalcid taxonomy? Systematic Entomology, 11, 75-82.

Jolicoeur, P. (1963) The multivariate generalization of the allometry equation. Biometrics, 19, 497-499.

Klimov, P.B., Lekveishvili, M., Dowling, A.P.G. \& Oconnor, B.M. (2004) Multivariate analysis of morphological variation in two cryptic species of Sancassania (Acari: Acaridae) from Costa Rica. Annals of the Entomological Society of America, 97, 322-345.

Klingenberg, C.P. (1996) Multivariate allometry. In: Marcus, L.F., Corti, M., Loy, A., Naylor, G.J.P. \& Slice, D.E. (Eds.), Advances in morphometrics. Plenum Press and NATO Scientific Affairs Division, New York, pp. $23-49$.

Krombein, K.V., Hurd, P.D., Smith, D.R. \& Burks, B.D. (1979) Catalog of Hymenoptera in America North of Mexico. Volume 1. Symphyta and Apocrita (Parasitica). Smithsonian Institution Press, Washington D.C, 1198 pp.

Kurdjumov, N.V. (1913) Notes on Pteromalidae (Hymenoptera, Chalcidoidea). Russkoe Entomologicheskoe Obozrenie, 13, 124.

Kusevska, M. (1977) Morphological chracteristics of Dibrachys fuscicornis Walk. (Hym., Pteromalidae) and his activity in relation to Euproctis chrysorrhoea L. (Lep., Lymantriidae) as a host. Fragmenta Balcanica Musei Macedonici Scientiarum Naturalium, 10 (6), 45-56.

Newman, E. (1863) Parasites and hyperparasites. Zoologist, 21, 8609-8610.

Norton, E. (1869) American Hymenoptera. Transactions of the American Entomological Society, 2, 321-368.

Noyes, J.S. (2003) Universal Chalcidoidea Database. Available from http://www.nhm.ac.uk/entomology/chalcidoids/ index.html (accessed 10 February 2010).

Peck, O. (1963) A catalogue of the nearctic Chalcidoidea (Insecta: Hymenoptera). The Canadian Entomologist, Supplement, $30,1-1092$.

Peters, R. (2007) Interaktionen zwischen Wirten und Parasitoiden: Nahrungsnetzstruktur, Wirtsspektren und Wirtsfindung am Beispiel der Arten aus Vogelnestern. Ph.D. thesis. University of Hamburg, Germany. Available from http://www.sub.unihamburg.de/opus/volltexte/2007/3234/pdf/DissertationPeters.pdf

Peters, R.S. \& Abraham, R. (2010) The food web of parasitoid wasps and their non-phytophagous fly hosts in birds' nests (Hymenoptera: Chalcidoidea, and Diptera: Cyclorrhapha). Journal of Natural History, 44, 613-626.

Pimentel, R.A. (1979) Morphometrics. The multivariate analysis of morphological data. Kendall/Hunt, Dubuque, Iowa, 276 pp.

Polaszek, A., Manzari, S. \& Quicke, D.L.J. (2004) Morphological and molecular taxonomic analysis of the Encarsia meritoria species-complex (Hymenoptera, Aphelinidae), parasitoids of whiteflies (Hemiptera, Aleyrodidae) of economic importance. Zoologica Scripta, 33, 403-421.

R Development Core Team (2010) R: A language and environment for statistical computing. R Foundation for Statistical Computing, Vienna, Austria. ISBN 3-900051-07-0, URL http://www.R-project.org.

Ratzeburg, J.T.C. (1844) Die Ichneumonen der Forstinsekten in entomologischer und forstlicher Beziehung. 1. Berlin, $224 \mathrm{pp.}$

Ratzeburg, J.T.C. (1848) Die Ichneumonen der Forstinsekten in entomologischer und forstlicher Beziehung. 2. Berlin, 238 pp.

Ratzeburg, J.T.C. (1852) Die Ichneumonen der Forstinsekten in entomologischer und forstlicher Beziehung. 3. Berlin, 272 pp.

Rencher, A.C. (2002) Methods of multivariate analysis. Wiley Series in Probability and Statistics, New York, 708 pp.

Reyment, R.A., Blackith, R.E. \& Campbell, N.A. (1984) Multivariate morphometrics (2nd edition). Academic Press, London, 233 pp. 
Rondani, C. (1876) Il nemico della tignuola della cera (Galleria cereana). Bollettino del Comizio Agrario Parmense, 9, 38-41.

Sharkov, A.V. (1982) The pteromalid Dibrachys boarmiae (Walker) (Hymenoptera, Pteromalidae), new to the USSR. Entomologiceskoe obozrenie, 61, 620-625.

Sharkov, A.V. (1983) A new species of the genus Dibrachys (Chalcidoidea, Pteromalidae) from the vicinity of Odessa. Zoologicheskiy Zhurnal, 62 (3), 452-453.

Sorensen, J.T. \& Foottit, R. (1992) Ordination in the study of morphology, evolution and systematics of insects. Applications and quantitative genetic rationals. Elsevier Science, Amsterdam, 426 pp.

Szelényi, G. (1981) New genera and species of Pteromalidae (Hymenoptera: Chalcidoidea) collected in the Hungarian National Park, Hortobágy. Acta Zoologica Academiae Scientiarum Hungaricae, 27, 399-406.

Thomson, C.G. (1878) Hymenoptera Scandinaviae. Tom. V. Pteromalus (Svederus) continuatio. Lund.

Venables, W.N. \& Ripley, B.D. (2002) Modern applied statistics with S (fourth edition). Springer, New York, 495 pp.

Vidal, S. (2001) Entomofauna Germanica. Band 4. Verzeichnis der Hautflügler Deutschlands. Chalcidoidea. In: Dathe, H.H., Taeger, A. \& Blank, S.M. (Eds.), Entomologische Nachrichten und Berichte Beiheft 7, pp. 51-69.

Walker, F. (1835) Monographia Chalciditum. The Entomological Magazine, 2, 476-502.

Wang, X.-H. \& Lester, P.J. (2004) A preliminary study of the usefulness of morphometric tools for splitting the Monomorium antarcticum (Smith) complex (Hymenoptera: Formicidae), New Zealand's most common native ants. New Zealand Entomologist, 27, 103-108.

Webster, F.M. (1883) Observations of the angoumois grain moth and its parasites. Report of the Illinois State Entomologist, 12, 151-152.

Yang, Z. (1996) Parasitic wasps on bark beetles in China [In Chinese with English summary]. Science Press, Beijing, China, 363 pp.

Zerova, M.D., Seregina, L.Y. \& Tsybulskh, A.I. (1986) The systematic position and host-parasite relations of Dibrachys cavus (Hymenoptera: Pteromalidae). Part I. Verstnik Zoologii, 2, 7-16.

\section{APPENDIX. Synopsis of valid species in Dibrachys Förster.}

Dibrachys (Allodibrachys) affinis Masi, 1907

Dibrachys (Dibrachys) braconidis (Ferrière \& Faure, 1925)

Dibrachys (Dibrachys) confusus (Girault, 1916)

Dibrachys (Dibrachys) crassiscapus Sharkov, 1983

Dibrachys (Dibrachys) fuscicornis (Walker, 1836)

Dibrachys (Allodibrachys) hians Bouček, 1965

Dibrachys (Allodibrachys) kojimae (Ishii, 1938)

Dibrachys (Dibrachys) koraiensis Yang, 1996

Dibrachys (Dibrachys) lignicola Graham, 1969

Dibrachys (Dibrachys) maculipennis Szelényi, 1957

Dibrachys (Dibrachys) microgastri (Bouché, 1834)

Dibrachys (Dibrachys) palandoekenus Doganlar, 1987

Dibrachys (Dibrachys) pelos Grissell, 1974

Dibrachys (Dibrachys) perversus (Walker, 1835), nomen dubium

Dibrachys (Dibrachys) relativus Doganlar, 1987

Dibrachys (Dibrachys) verovesparum Peters \& Baur, 2011

Dibrachys (Allodibrachys) yunnanensis Yang, 1996 